\title{
CONCEPTUALIZACIÓN DE LOS CONTRATOS \\ INTELIGENTES O AUTOEJECUTABLES BASADOS EN LA \\ TECNOLOGÍA BLOCKCHAIN Y SU ENCUADRE EN EL ORDENAMIENTO JURÍDICO ESPAÑOL
}

\author{
CONCEPTUALIZATION OF INTELLIGENT OR SELF- \\ EXECUTING CONTRACTS BASED ON BLOCKCHAIN \\ TECHNOLOGY AND THE SPANISH LEGAL SYSTEM
}

Adoración CASTELLANO GARCÍA ${ }^{1}$

Universidad de Jaén, España

Recibido: 01 Junio 2021 / Aceptado: 18 Junio 2021

\section{Resumen}

En el sector de la contratación electrónica, desde hace unos años se ha potenciado el uso de los denominados contratos inteligentes o autoejecutables, debido a que el desarrollo de la innovadora tecnología de la cadena de bloques ha revolucionado su ámbito de aplicación. Como consecuencia del auge experimentado,desde el punto de vista jurídico se han planteado distintos interrogantes tendentes a dilucidar si son contratos que deben regirse por la normativa legal vigente o no. Y ello en base, tanto a su proceso de formación y perfección, como a las particularidades que caracterizan su ejecución, en la cual, destacan instrumentos de pago electrónicos como las criptodivisas.

Palabras clave: Contratos inteligentes, Cadena de bloques, Autoejecución, Contrato electrónico, Código

\begin{abstract}
In the sector of electronic contracts or concluded electronically, the use of so-called smart or self-executing contracts has been promoted in recent years, due to the fact that the development of innovative blockchain technology has revolutionized its field of application. As a consequence of the boom experienced, different questions have been raised from the legal point of view tending to elucidate whether they are contracts that must be governed by the current legal regime or not. And this based on both its training and perfection process, as well as the particularities that characterize its execution, in which electronic payment instruments such as cryptocurrencies stand out.
\end{abstract}

Keywords: Smart contracts, Blockchain, Self-execution, Electronic contract, Code 
SUMARIO: I. Principios fundamentales de la cadena de bloques. II. Delimitación conceptual y funcional de los denominados contratos inteligentes. 1. Origen, tipologías y concepto. 2. Funcionamiento y ventajas/ inconvenientes derivados del mismo. III. ¿Es posible encuadrar los contratos autoejecutables en el régimen jurídico que resulta de aplicación a los contratos tradicionales?: El proceso de formación. 1. Fase de emisión de la oferta contractual. 2. Fase de aceptación de la oferta contractual o perfeccionamiento del contrato. 3. Fase de ejecución: pagos electrónicos con criptomonedas y dinero electrónico. IV. Conclusión. V. Bibliografía.

SUMMARY: I. Fundamental principles of the blockchain. II. Conceptual and functional delimitation of so-called smart contracts. 1. Origin, typologies and concept. 2. Functioning and advantages/disadvantages derived from it. III. Is it possible to frame self-executing contracts in the legal regime that is applicable to traditional contracts?: The training process. 1. Issuance phase of the contractual offer. 2. Phase of acceptance of the contractual offer or completion of the contract. 3. Execution phase: electronic payments with cryptocurrencies and electronic money. IV. Conclusion. V. Bibliography.

\section{PRINCIPIOS FUNDAMENTALES DE LA CADENA DE BLOQUES}

El Foro Económico Mundial, en un informe del año $2015^{2}$ comentaba que uno de los puntos de inflexión de la era o sociedad digital venía dado por el auge de la llamada Blockchain o cadena de bloques, esto es, un novedoso software conocido a nivel global especialmente porque sobre él se articula el funcionamiento de las monedas digitales. Muy recientemente, dicho ente ha vuelto a pronunciarse sobre la materia, ${ }^{3}$ y en esta ocasión se ha detenido a conceptualizar la tecnología de la que trae causa aquella, cual es, la tecnología de registro distribuido (DLT, en adelante). Así, la define como una base de datos distribuida e inmutable que gobierna el flujo de datos entre los participantes descentralizados. Además, ha situado su fundamento en cuatro elementos, a saber: el libro mayor distribuido en una red de pares o iguales, las firmas electrónicas dotadas del cifrado hash, un algoritmo de consenso y los contratos inteligentes.

Con carácter previo a que nos adentremos en el análisis de cada uno de los principios enumerados, apreciamos esencial mencionar que es muy usual encontrar pronunciamientos doctrinales que equiparan la DLT y la cadena de bloques, no obstante, realmente la primera subyace a la segunda. Esto significa que, la tecnología DLT es única y no siempre se aplica en una blockchain, por 
el contrario, toda blockchain emplea DLT, en la medida en que es una de sus tipologías más destacadas.

Una vez dispuesto este matiz tan importante, a los efectos de contextualizar someramente estas realidades, hay que decir que "entenderemos por 'Registro distribuido' a aquel registro que se construye de forma que las anotaciones que lo conforman se consensuan entre los anónimos intervinientes en su creación. Además, cada uno de ellos cuenta con una copia actualizada de este Registro, que es único y universal". ${ }^{4} \mathrm{Y}$ también procede señalar que "antes de que existiera la tecnología DLT y el blockchain, cualquier transacción online dependía de un intermediario (...) que asegurara de manera centralizada que la transferencia de activos se había efectuado correctamente (...). Las tecnologías DLT surgen como una alternativa al sistema tradicional de control centralizado, permitiendo controlar las transacciones de manera descentralizada a través de una red con miles de ordenadores conectados (...) y posibilitando a los usuarios interactuar con activos digitales a través de un sistema de transacciones (...) $P 2 P P^{\circ} .{ }^{5}$ A este respecto, cabe puntualizar que la red P2P, Peer-to-Peer, red de pares, red de o entre iguales se concibe como una "red descentralizada sin clientes ni servidores fijos, que cuenta con una serie de nodos que funcionan simultáneamente como clientes y servidores de los demás nodos de la red, cada uno de los cuales puede iniciar, detener o completar una transacción compatible". ${ }^{6}$

Además de las conceptualizaciones reseñadas podríamos traer a colación otras muchas, si bien, el nexo común de todas ellas es la novedad que incorporan en su aspecto subjetivo. Mientras que en los sistemas tradicionales concurre un ente central encargado tanto de la supervisión de todo lo operado en el mismo, como de asegurar el correcto desempeño del régimen de garantías que ofrece, en aquellos que tienen carácter descentralizado "no existe dicho intermediario-supervisor: son los propios usuarios del sistema los que supervisan y admiten las operaciones (...). El control es posible gracias a la existencia de una base de datos única, de construcción colectiva, compartida por todos los nodos (o 'mineros') que utilizan el sistema". ${ }^{7}$ Ahora bien, todos esos nodos no tienen la misma categoría o función, pues la doctrina contempla varias clasificaciones. De un lado, se diferencia entre:

"Nodos completos: Son aquellos nodos que almacenan (...) todas las transacciones (...) que hayan ocurrido en la cadena de bloques. Además, controlan el cumplimiento de todas las normas en el mecanismo de consenso y comprueban que todas las transacciones sean correctas. 
Nodos ligeros o parciales: Son aquellos nodos que no almacenan el libro completo localmente. (...) Estos nodos dependen de la verificación de los nodos completos para garantizar su seguridad (...).

Nodos mineros: Compiten para generar nuevos bloques ejecutando hardware especializado para resolver el algoritmo de prueba de trabajo. Algunos nodos mineros son nodos completos, manteniendo una copia completa de la cadena de bloques, mientras que otros son nodos ligeros que participan en la minería de agrupaciones y dependen de un servidor de agrupaciones para mantener un nodo completo".

Y de otro lado, con una perspectiva mucho más simplista, entre nodos "normales, a los que se llama monederos, que se limitan a guardar información de un usuario y enviar transacciones. (Y) (...) los que guardan el libro de contabilidad y anotan las transacciones que se denominan "mineros". 9 En nuestra opinión, esta segunda distinción agrupa como nodos normales a los completos y a los parciales, que tienen en común la ausencia de tareas de ejecución de bloques.

Sentado lo anterior, tenemos plena certeza de que la cadena de bloques constituye "uno de los protocolos informáticos bajo los que opera la Tecnología de Registro Distribuido, que podríamos definir como una base de datos descentralizada que almacena un registro de activos y transacciones en unos equipos interconectados a través de una red de ordenadores distribuidos, llamados nodos". ${ }^{10}$ Si bien, la doctrina ${ }^{11}$ entiende que la particularidad más destacada que diferencia la Blockchain del resto de bases de registro que utilizan la DLT, es su forma de funcionar o de integrar la información (a la que nos vamos a referir a continuación), por cuanto "es sellada a lo largo de una cadena de bloques gracias a un algoritmo de encriptación" (procediendo de ahí el origen de su nombre). En concreto, "los bloques se cierran con una firma criptográfica llamada hash; ${ }^{12}$ el siguiente bloque se abre con ese hash, a modo de sello lacrado. De esta forma, se certifica que la información, encriptada, no se ha manipulado ni se puede manipular. Cada vez que se agrega un bloque a la cadena, se vincula al bloque inmediatamente precedente, lo que imprime un orden temporal a los registros que viene determinado por el momento de inclusión en la blockchain". 13 Es decir, "los bloques se conforman de tal manera que cada bloque nuevo está criptográficamente conectado al bloque anterior". 14

Al margen de las consideraciones expuestas, hay que distinguir entre varios tipos de Blockchain, cuales son: las de carácter público, en las que "cualquier persona puede acceder, puede crear bloques y puede participar en el proceso 
de consenso o proceso de validación"; ${ }^{15}$ las de carácter privado, donde "solo pueden participar usuarios que previamente hayan sido seleccionados $y$ cuenten con autorización para visualizar y/o encriptar nuevos datos en la cadena, estando restringido el acceso a terceras partes"; ${ }^{16}$ y las híbridas o de consorcio, en donde "el proceso de consorcio es controlado por un conjunto de nodos preseleccionados (...) (y) la lectura puede ser pública o restringida a los participantes". ${ }^{17}$

De las tres modalidades mencionadas, nos vamos a centrar en la pública, ya que nuestro ámbito de estudio se circunscribe a redes puramente descentralizadas, que son las utilizadas por algunas de las monedas virtuales más conocidas como Bitcoin o Ethereum, y por consiguiente, las que se emplean en la suscripción de contratos inteligentes concluidos con estas, como veremos más adelante.

Genéricamente, una cadena de bloques pública es concebida como "un sistema contable o una base de datos capaz de registrar cualquier tipo de información a través de internet". ${ }^{18}$ Dicho sistema "emplea el protocolo $P 2 P(\ldots)$ en el que los nodos que conforman la red se comportan como iguales entre sí, permitiendo que cada nodo se comunique con otros de forma directa, y sin que exista un nodo central o dominante. Los nodos trabajan de forma colaborativa para custodiar y compartir el registro de datos y transacciones que ya se han producido, así como para validar y asegurar que las nuevas transacciones son correctas". ${ }^{19}$ En lo relativo a su funcionamiento, resulta que cuando se producen "transacciones económicas entre dos sujetos (...) la validación corresponde a todos los usuarios (...) que participan en la red a través de un ordenador. (...) El proceso a través del cual la información contenida en un bloque es encadenada y sincronizada en todos los ordenadores de los nodos de la red es conocido como consenso o minado (mining)". En concreto, "minar es el proceso de invertir capacidad computacional para procesar transacciones, garantizar la seguridad de la red, y conseguir que todos los participantes estén sincronizados (...) usando un hardware especializado" ${ }^{20} \mathrm{O}$ sea, la tarea de los mineros consiste en verificar las operaciones que se producen en la cadena de bloques para que queden válidamente incorporadas a esta, lo cual tiene lugar mediante la resolución de complejos problemas matemáticos a cambio de una determinada cantidad de monedas virtuales que obtendrán como compensación por su labor. Para ello, estos nodos necesitan tener conocimientos específicos en la materia, además de disponer de un ordenador capaz de para procesar la tecnología que se utiliza, por cuanto, el inicio de este proceso tiene lugar con la instalación en el equipo de un software o programa informático de código abierto o libre, 
cuya descarga, instrucciones de programación y funciones tienen carácter público. ${ }^{21}$ No obstante, "a pesar de que, en principio, la filosofía de la red distribuida ofrece la posibilidad de que cualquier ordenador pueda participar activamente del proceso (...), la elevada capacidad computacional requerida implica que, en la práctica, esta actividad esté dominada por un reducido grupo de actores". 22

Asimismo, en lo que se refiere al aspecto técnico del minado, cabe destacar que utiliza el conocido como protocolo Proof of Work, que "consiste en un algoritmo basado en una lotería que avanza a través de una serie de rondas donde en cada una selecciona un nodo aleatorio en función de su poder de computación para validar un bloque de transacciones". ${ }^{23}$ Así, "cuando un nodo obtiene el valor objetivo transmite el bloque a los demás nodos en la red y estos deben confirmar mutuamente la exactitud del valor hash, de modo que si se valida el bloque los demás nodos deben agregarlo a su copia local de Blockchain". ${ }^{24}$ Lo cual, sólo sucederá en caso de que se evidencie la ausencia de esas transacciones en un bloque previo. ${ }^{25}$ En suma, una vez que existe consenso sobre la validez de la transacción ejecutada, esta se incorpora a la cadena de bloques, con la consiguiente actualización automática para todos y cada uno de los nodos de la red P2P de su copia del historial del sistema.

En consonancia con las consideraciones expuestas, desde una perspectiva práctica, la cadena de bloques se vislumbra como un conjunto de "procedimientos codificados [...] que acreditan la existencia de eventos y manifestaciones ocurridas en la red", ${ }^{26}$ por cuanto, su finalidad "consiste en almacenar en registros contables encriptados la información referente a una transacción económica. (...) Explicado de una forma poco ortodoxa se podría decir que estamos ante un macro libro de contabilidad que se halla en el panorama virtual y sus registros son protegidos por potentes algoritmos informáticos". ${ }^{27}$ Es decir, no solo "permite grabar los movimientos que se producen entre usuarios", ${ }^{28}$ sino también "transferir elementos de valor (en forma de criptomonedas, información, etc.) (...) y, en las versiones no centralizadas, sin la necesidad de una autoridad única que valide dichas transferencias". ${ }^{29}$ Por ello, se afirma que "las aplicaciones de la tecnología blockchain trascienden la mera transacción de bitcoins", ${ }^{30} \mathrm{y}$ en este sentido también se ha interpretado que "el smart contract constituye, en efecto, sólo una de las múltiples aplicaciones que admite la tecnología blockchain". 31 A este respecto, en lugar de considerar que los contratos inteligentes son un elemento de la DLT, tal y como mencionamos al inicio del presente epígrafe que dispuso el Foro Económico Mundial, apreciamos más correcto analizarlo 
como uno de sus diversos usos y así vamos a proceder en los siguientes apartados.

\section{DELIMITACIÓN CONCEPTUAL Y FUNCIONAL DE LOS DENOMINADOS CONTRATOS INTELIGENTES}

\section{ORIGEN, TIPOLOGÍAS Y CONCEPTO}

En la década de los 90, el criptógrafo e informático estadounidense Nick Szabo publicó en la revista Extropy un artículo, ${ }^{32}$ en el que sintetizaba una serie de conceptos e ideas que conforman la base primigenia de los contratos desarrollados en plataformas digitales. A este respecto, parte de considerar que el contrato es un conjunto de promesas o pactos que constituyen la vía tradicional de formalizar una relación. No obstante, matiza que gracias a la revolución digital han surgido nuevas maneras de formalizar las relaciones, cuales son, los contratos inteligentes, que se aprecian más funcionales que los tradicionales en formato físico. Esta realidad se concibe como un conjunto de promesas en soporte digital, que puede contener una gran variedad de estipulaciones contractuales e incluso prohibir o encarecer el incumplimiento. ${ }^{33}$ Esto es, el autor infiere el contrato como la forma más típica de concretar pactos o promesas y constituir relaciones jurídicas, si bien, su carácter tradicional es opacado por los contratos inteligentes, que son las innovadoras vías de contratación emanadas del desarrollo tecnológico.

Este pronunciamiento, ha sido objeto de análisis doctrinal, y podemos encontrar a quien opina que "se trata de una definición aséptica, que incide en la programación de una acción que se llevará a cabo en las circunstancias especificadas. En otras palabras, la 'promesa' (...) no ha de revestir carácter vinculante, al menos desde una perspectiva jurídica". ${ }^{34}$ En consonancia, se ha considerado que hay tres elementos que deben ser objeto de matización: "En primer lugar, el contrato inteligente como un conjunto de promesas. Con ello (...) podríamos plantearnos qué sentido tiene hablar de -promesarespecto de algo que no se puede incumplir, por cuanto su realización se ha automatizado. (...) El segundo elemento (...) es la especificación del conjunto de promesas en forma o formato precisamente digital, lo que no resulta especialmente clarificador, (...) porque un smart contract no es sólo un contrato digitalizado, sino, además - programado-. Y el tercer elemento del concepto son unos -protocolos-que integrarían o se incluyen en el smart contract, y en los que o mediante los cuales las partes ejecutan, realizan o cumplen (...) las promesas. (...) El protocolo informático daría lugar al

Revista de Estudios Jurídicos, UJAEN, España $\mid$ AÑO 2021 |NUM. 21, e6756 | ISSN 1576-124X 
cumplimiento automático de lo acordado, cuando llegue una determina fecha o se produzca un determinado evento". ${ }^{35}$

A nuestro parecer, la originalidad y funcionalidad que ya se apreciaba en los contratos inteligentes como instrumentos de contratación, deviene de la automatización de su ejecución. O sea, de la capacidad de configurar un protocolo o programa informático que, de un lado, contenga, tanto la totalidad de las cláusulas que vayan a integrar el contrato, como los mecanismos necesarios para procurar que no quepa el incumplimiento de aquellas, o en caso de permitirse, sea lo más gravoso posible para quién infringe lo pactado. Y de otro, permita programar los eventos que propician la puesta en marcha del sistema. A título ejemplificativo, en el supuesto de las transacciones de prestación de servicios, afirmaba Szabo que necesitamos un protocolo que garantice que prestará el servicio si el pago se realiza, y viceversa. ${ }^{36}$ Es decir, ambos hechos (prestación del servicio y pago del precio estipulado) se encontrarían correlacionados, hasta el punto de que el sistema o protocolo digital de forma automática debería detectar si se cumplen o no los extremos, respondiendo en consecuencia con los efectos pertinentes previstos para cada caso.

A pesar de la entidad del juicio reseñado, cabe señalar que en los años inmediatamente siguientes no se hizo especial hincapié en el tema, por tratarse de una época donde la tecnología informática se encontraba aún en vías de desarrollo, y no había sido concebido el protocolo ideal en el que sustentar el funcionamiento de los contratos autoejecutables. Hubo que esperar hasta la creación de la moneda virtual descentralizada más conocida en la actualidad, Bitcoin, que se remonta al año 2009, para encontrar una conexión entre los esbozos del contrato inteligente y una materia en la que resultara viable su encuadre. ${ }^{37} \mathrm{Y}$ es que, esta nueva realidad surgida en el ámbito de los medios de pago electrónicos, se encuentra "amparada en una de las tecnologías más innovadoras del momento -la blockchain o cadena de bloques-", 38 la cual, constituye su protocolo de actuación, y vino a aportar al entorno digital una herramienta electrónica idónea para los contratos inteligentes. Si bien es cierto que, no es la única que emplean para funcionar, pues "el concepto de smart contract no se encuentra necesariamente ligado a la blockchain. Es concebible la existencia de (...) smart contracts en un entorno informático centralizado y no distribuido". ${ }^{39}$ A este respecto, resulta que "aunque existe tendencia a identificar los Smart contract con formatos que usan la llamada tecnología de bloques (...), lo cierto es que conforme a un patrón de neutralidad tecnológica podemos considerar como Smart contract a cualquier acuerdo en el que se formalicen todas o algunas de sus cláusulas mediante Scripts 
o pequeños programas, cuyo efecto sea que, una vez concluido el acuerdo y señalados uno o varios eventos desencadenantes, la producción de los eventos programados conlleva la ejecución automática del resto del contrato, sin que quepa modificación, bloqueo o inejecución de la prestación debida". ${ }^{40}$ En consonancia con este discernimiento, en el ámbito doctrinal podemos hallar distintas formas de clasificar los contratos autoejecutables:

De un lado, se afirma que "es posible aludir a dos modalidades de contratos inteligentes: los llamados smart code contracts y los smart legal contracts. Los primeros aluden a las secuencias de código que son todo o parte de un acuerdo existente y que están almacenadas, verificadas y ejecutadas en una cadena de bloques (...). Los segundos (...) constituyen secuencias de código que expresan todo o parte de un acuerdo, pero no están registradas ni se ejecutan en una cadena de bloques; serían, por tanto, una alternativa más próxima a los 'contratos tradicionales', usualmente recogidos por escrito". ${ }^{41}$ A nuestro parecer, las principales diferencias entre ambos estriban en la tecnología que utilizan para registrar y ejecutar el acuerdo al que dan soporte (que sería la Blockchain u otras opciones existentes, respectivamente), y en las posibilidades que ofrecen como consecuencia de la misma. Y ello por cuanto, "cuando los contratos inteligentes son considerados desde la perspectiva de la cadena de bloques se adicionan capacidades a los acuerdos autoejecutables en función del software contractual, como pueden ser:

- Incorporar de manera ágil los nuevos datos que pueden formar parte del contenido de las cláusulas, términos y condiciones o quedar al margen de ellas.

- Procesar tales datos para producir consecuencias jurídicas en función de lo estipulado en el clausulado (asociar a datos externos -input- una consecuencia en virtud de lo acordado -output-).

- Preparar, adoptar e implementar diferentes medidas e instrumentos eficientes de coerción, o de pago de indemnizaciones". ${ }^{42}$

$\mathrm{Y}$ de otro lado, se ha distinguido entre contratos autoejecutables fuertes, que son aquellos que imponen un coste prohibitivo a la revocación o modificación contractual por parte de un tribunal o de los propios contratantes; y contratos inteligentes débiles, que no contienen dicha previsión, y por tanto permiten alterar con cierta facilidad el contrato ya ejecutado. ${ }^{43}$ Este argumento se ve reforzado con la extrapolación de otra distinción realizada entre métodos de ejecución de carácter tradicional y, no tradicional, siendo los primeros los que actúan a través de instituciones como el arbitraje o los tribunales de justicia; 
y los segundos, los que se sustentan en una tecnología creada a prueba de manipulaciones. ${ }^{44}$ La combinación de ambas tipologías supone calificar como contratos inteligentes fuertes a los de carácter no tradicional, en la medida en que basándose en la tecnología inmutable prohíben o imponen un elevado coste a cualquier alteración de las estipulaciones o instrucciones previamente sentadas. Y por contra, serán débiles los de índole tradicional, que no están dotados de dichas previsiones y por ello pueden ser objeto de modificación por las partes o por las autoridades que actúen como terceros.

En nuestra opinión, se puede apreciar una correspondencia entre los smart code contracts, y los contratos inteligentes calificados como fuertes y no tradicionales, los cuales se refieren en conjunto a los contratos autoejecutables basados en la cadena de bloques. Y ello por cuanto, es "la aplicación que combina las características del contrato tradicional con las ventajas ya referidas del blockchain y además se le añade la capacidad de auto-ejecución de las condiciones y prestaciones acordadas por las partes sin necesidad de la participación de las mismas, lo que prácticamente garantiza el cumplimiento de las condiciones acordadas". ${ }^{45}$ En definitiva, cabe matizar que en el presente artículo nos vamos a centrar en esta categoría, en la medida en que, como ya anticipamos, es la que mayor controversia suscita por la descentralización que la caracteriza y por la posibilidad que ofrecen de programar pagos electrónicos sin necesidad de intermediarios.

Sentado lo anterior, de todas las consideraciones introductorias expuestas, deducimos que son diversas y complejas las cuestiones que demandan un análisis, y necesariamente debemos partir de cómo se han conceptualizado los contratos inteligentes a raíz de la relevancia adquirida. Para ello vamos a acoger una perspectiva que compagina lo jurídico con lo tecnológico, pues es fundamental comprender a qué nos referimos "materialmente" cuando hablamos de este fenómeno, lo cual, necesariamente nos conduce a emplear ciertos términos del argot informático, así sea mínimamente por la índole legal de este trabajo.

Para encontrar una definición legalista de smart contract en el ámbito europeo debemos remitirnos al ordenamiento jurídico italiano, ${ }^{46}$ donde el legislador lo concibe como un programa informático que opera sobre tecnologías basadas en registros distribuidos y cuya ejecución une automáticamente dos o más partes sobre la base de efectos predefinidos. Asimismo, se considera que los contratos inteligentes no satisfacen el requisito de la forma escrita hasta tanto se produce la identificación informática de los interesados. A nuestro parecer, esta noción es acertada en toda su extensión, no solo porque contempla una equiparación formal entre el contrato en soporte 
físico (papel) y el contrato en soporte digital. Lo cual supone que ambas modalidades despliegan plenamente efectos jurídicos, y ello se corresponde con el principio de equivalencia funcional que rige la contratación electrónica en la normativa española. ${ }^{47}$ Sino también, porque se encuentra en total consonancia con la doctrina mayoritaria que fundamentalmente orienta los smart contracts hacia dos vertientes:

a) La óptica informática o técnica, donde se dispone que "un smart contract sería una secuencia de código y datos que efectúa la operación en su caso prevista" ${ }^{48}$ y que, a su vez, "puede designar desde contratos o cláusulas contractuales en lenguaje natural trasladados a código informático hasta casos más complejos representados y ejecutados directamente por scripts". ${ }^{9}$ O sea, esta visión se centra en recalcar que se trata de "programas informáticos, piezas o unidades de software, instrucciones mediante las que opera una máquina o un sistema. (...) Podríamos decir que es puro algoritmo, por cuanto su rasgo característico no es precisamente la flexibilidad, sino la rigidez, el automatismo, el seguimiento riguroso de las instrucciones de un programa". ${ }^{0}$

b) La perspectiva objetiva, en la cual se entiende que un contrato inteligente es "un programa informático que ejecuta acuerdos establecidos entre dos o más partes de modo que ciertas acciones se efectúan como resultado de que se cumplan una serie de condiciones específicas. Esto es, cuando se da una condición programada con anterioridad, el contrato inteligente ejecuta automáticamente la cláusula correspondiente. (...) Por tanto, (...) se programan las condiciones, se firman por ambas partes implicadas y se 'coloca' en una Blockchain para que no pueda modificarse". ${ }^{51}$ A esta concepción responde el juicio encaminado a sentar que en un contrato autoejecutable "las partes definen el objeto del contrato, las acciones que se pueden realizar sobre él y sus cláusulas de aplicación, que incluyen habitualmente transacciones financieras. El programa se encarga de verificar el cumplimiento de las condiciones acordadas y ejecutar las prestaciones asociadas sin intervención de un tercero". ${ }^{52}$

Asimismo, se afirma que un contrato inteligente es un acuerdo cuya ejecución está automatizada a través de una computadora que ejecuta un código que ha traducido la prosa legal en un programa ejecutable, el cual, tiene control sobre los bienes físicos o digitales necesarios para llevar a cabo la ejecución $\mathrm{y}$, por tanto, no depende del estado, sino que es una forma de que los contratantes garanticen el desempeño. ${ }^{53}$ Es decir, "los smart contracts son la codificación de los términos de un contrato celebrado por las partes dentro de la red o cadena de bloques", además de "la revelación virtual de los 
contratos clásicos que recoge el Derecho privado en un lenguaje encriptado cuya ejecución está previamente programada para que se auto ejecute gracias a un código que contiene el algoritmo de la transacción". ${ }^{44}$

En consonancia, hay quién estima que "con el término 'contratos inteligentes' aludimos a aquellos acuerdos productores de efectos jurídicos cuya peculiaridad esencial es que son 'autoejecutables' por estar total o parcialmente recogidos en secuencias de código: la ejecución del contenido no depende de la voluntad de las partes, sino que tiene lugar de manera automática, una vez se dan las condiciones preestablecidas por aquellas". No obstante, hay que tener en cuenta que "este tipo de contratos no admite cláusulas que necesiten de interpretación para ser verificadas -buena fe, consumidor medio, diligencia debida, interés superior del menor, etc.-, ni tampoco tienen perfecta cabida en ellos conceptos como 'caso fortuito' o “fuerza mayor". ${ }^{55}$ La razón de ser de esta limitación reside en que, a pesar de los grandes avances tecnológicos que han acaecido en los últimos años, los dispositivos electrónicos siguen siendo máquinas que actúan mecánicamente y no cuentan con la capacidad de interpretar las instrucciones que se insertan en ellos, por lo cual, los términos del contrato deben ser objetiva y no discrecionalmente verificables.

En conclusión, entendemos que los contratos autoejecutables son una aplicación o programa desarrollado en el ámbito informático, el cual contiene las condiciones que integran un determinado contrato, y que al insertarse en una blockchain confiere a esta el poder de controlar el cumplimiento de las mismas. Solo en caso de verificarse dichos términos en su totalidad, tendrá lugar la ejecución automática de la relación contractual, la cual, se produce siguiendo unas instrucciones previamente sentadas en la red. De este modo, resulta que no es necesaria la intervención manual de las partes ni tampoco de terceros ajenos a la transacción (intermediarios profesionales, autoridades...) y con ello se garantiza su seguridad e inmutabilidad. Por tanto, la confianza en este sentido necesariamente ha de residir en la propia configuración de dicho programa.

A modo de resumen, consideramos interesante traer a colación una síntesis de las características más clarificadoras del smart contract, realizada por el Consejo General de la Abogacía Española, ${ }^{56}$ donde lo concibe como "un registro digital que une dos o más partes especificando las condiciones de ejecución. Está basado en la tecnología blockchain y el principio de los registros distribuidos. Es autónomo y automatizado (...) y (...) tiene la particularidad de ser: Público (cualquiera puede comprobar la buena ejecución del contrato); Seguro (por el sistema de encriptación de 
blockchain); Inmutable (los datos registrados en blockchain lo están para siempre, no son modificables (...)); Fiable (siempre está disponible por la redundancia del soporte de blockchain). Es el propio sistema que asegura la ejecución de la transacción y no las partes implicadas. Gracias a ello no se necesita un tercero para su interpretación".

\section{FUNCIONAMIENTO Y VENTAJAS/INCONVENIENTES DERIVADOS DEL MISMO}

Una vez dispuesto lo que se entiende por contratos inteligentes, hay que analizar cómo funcionan, o lo que es lo mismo, cuáles son las fases en las que se configuran. Para ello, necesariamente debemos partir de cómo se gestan o generan, y en este sentido al igual que sucede con los contratos tradicionales, "cuando se contrate con consumidores, el predisponente habrá de asegurar la previa entrega de la información pre-contractual a estos antes de la perfección. La normativa en vigor ya prevé para los contratos no inteligentes que la entrega de esta información se realice en soporte duradero'.$^{57}(\ldots)$ Además, cuando el contrato sea inteligente, quien lo predisponga tendrá que incorporar una cláusula en la que el adherente consienta en la codificación de los pactos y en la subsiguiente ejecución automática de los mismos". ${ }^{58} \mathrm{~A}$ continuación tiene lugar la negociación de los términos que van a integrar el contrato, y concluida la misma, se procede a su redacción. En este punto es fundamental decidir de qué forma se va a trasladar la información que ha sido plasmada en el contrato redactado en lenguaje humano, a un programa o aplicación que utiliza lenguaje de programación informático, código o script. ${ }^{59}$ La importancia de esta cuestión se debe a que en el ámbito doctrinal "se dice que en los smart contracts el código es la ley. El contrato se rige por el código informático" ${ }^{60}$ distinguiéndose varias formas de crear ese código:

En primer lugar, se han desarrollado plataformas digitales en las que directamente se genera el contrato inteligente en lenguaje máquina, si bien, esta opción se encuentra limitada a usuarios expertos en el uso de dichas aplicaciones y que sean conocedores de su lenguaje propio, porque de lo contrario no podrían gestionar aquellas por no entender el código.

En segundo lugar, existen otras plataformas donde por medio de un formulario o plantilla se insertan en nuestro lenguaje propio las condiciones contractuales y automáticamente son traducidas o volcadas a código informático, momento en el que dejan de ser legibles para las personas.

Y, por último, se contempla la posibilidad de utilizar los contratos ricardianos, cuales son, aquellos con "formato de documento digital que 
actúan como un acuerdo entre dos partes sobre los términos y condiciones para una interacción entre las partes acordadas (...). Lo que lo hace único es que aunque está firmado y verificado criptográficamente también es un texto legible para personas (pues) (...) establece una conexión entre la legislación y el mundo digital (...) convirtiendo un contrato legal y legible por personas en un código de software legible por una máquina". ${ }^{61}$

Cuando el contrato se encuentra incorporado en la Red en el lenguaje código, está a disposición de los usuarios de la Blockchain para ser perfeccionado mediante el empleo de "la firma electrónica avanzada ${ }^{62}$ basada en criptografía de clave asimétrica, que es la inicialmente prevista para formalizar los contratos inteligentes" ${ }^{63}$ A título ejemplificativo, podemos citar el supuesto de la compraventa de una aplicación informática donde se emplea como medio de pago una moneda virtual. En este caso, si las partes cumplen lo pactado, o sea, el comprador transfiere la criptomoneda al servidor del smart contract y el vendedor envía el software solicitado al mismo lugar, el sistema procederá a la verificación de las prestaciones. Solo si dichas premisas se han cumplido llega la fase de consumación del contrato, donde este se autoejecuta, es decir, siguiendo con el ejemplo, lo que sucede es que se transfiere la criptodivisa al vendedor y el programa informático al comprador. La operación queda concluida al dejarla registrada, lo cual se materializa con la creación de un nuevo eslabón en la cadena de bloques que contiene el resultado de la transacción ejecutada. Por el contrario, si alguna de las prestaciones no se ha cumplido el contrato no llega a consumarse ni registrarse en la Blockchain, porque este instrumento tiene la capacidad de verificar por sí mismo si se cumplen o no las condiciones que se le han incorporado, así como de ejecutar los efectos previstos para cada supuesto.

Como consecuencia de las pautas de funcionamiento expuestas, podemos apreciar una serie de diferencias respecto a la contratación tradicional, distinguiendo, por un lado, las que constituyen una ventaja a favor de los contratos inteligentes, cuales son:

La inmutabilidad o invariabilidad, que permite una mayor confianza entre los contratantes, en la medida en que confiere total certeza tanto de la identidad de las partes, como de la imposibilidad de operar cualquier tipo de alteración sobre las estipulaciones del contrato. Ello incluye desde la novación de los términos, hasta la resolución contractual, porque "el sistema de cadena de bloques hace imposible una modificación retroactiva. No es posible modificar la información encriptada insertada en la cadena. Si se hiciese en un nodo de esta, los demás no validarían la información y quedaría fuera de la cadena, sin valor ni efecto alguno". ${ }^{64} \mathrm{Si}$ a esta circunstancia sumamos la transparencia 
que caracteriza a la tecnología Blockchain, especialmente en lo que se refiere al historial de transacciones, se afianza aún más la seguridad sobre la dificultad de que se produzcan usos indebidos o manipulaciones de los datos contenidos en el registro. ${ }^{65}$

Y el ahorro en los costes devengados por las transacciones, destacando especialmente los relativos a la reclamación judicial ante el incumplimiento de alguna de las partes, que en el caso de los smart contracts no se generan por la carencia de intermediarios derivada de la autoejecución que los caracteriza. ${ }^{66}$ O sea, a diferencia de lo que sucede con los contratos tradicionales, en los cuales, cuando se produce un incumplimiento por parte de alguno de los contratantes hay que acudir a un tercero para que imponga la ejecución forzosa de lo pactado, en el caso de los contratos inteligentes no es necesaria dicha intermediación. Y ello por cuanto, son "herramientas que permiten la ejecución automática e independiente de aquellos términos de un contrato que sean objetivables (...) y que hacen que sus cláusulas sean vinculantes, imparables y automáticas (...). Además permiten garantizar la ejecución de un contrato (...), entregar bienes digitales, eficientar la entrega de bienes reales y servicios". ${ }^{67}$ No obstante, y en consonancia con la característica referida en el párrafo anterior, podemos encontrar opiniones ${ }^{68}$ tendentes a defender que la entidad del ahorro que producen los contratos autoejecutables no es especialmente relevante si tenemos en cuenta lo que sucede en materia de modificaciones contractuales. Esto es, en caso de que las partes deseen modificar en un sentido concreto el contrato inteligente, solo podrán hacerlo si han contemplado dicha posibilidad en el mismo como distintas alternativas entre las que escoger de forma automatizada. De lo contrario, la única opción que tienen es redactar un nuevo smart contract que integre el cambio que desean operar. Ambas posibilidades conllevarían un gasto mayor, la primera en la etapa de confección o generación (por la especialización de los recursos empleados) y la segunda en la etapa de ejecución o consumación (por la necesidad de una doble formalización contractual).

Y, por otro lado, aquellas circunstancias que se vislumbran como inconvenientes de los contratos autoejecutables, a saber:

La carencia de auto interpretación y adaptación, por cuanto estos contratos no tienen capacidad de analizar de forma autónoma las distintas situaciones que se pueden originar en el ámbito de la contratación y actuar en consecuencia. Es decir, solo se rigen mecánicamente por las instrucciones insertas en ellos, las cuales, deben ser plenamente objetivables no dejando espacio al análisis de ambigüedades. Por el contrario, ante cualquier controversia acaecida offline dicha tarea recae sobre los juristas, y en última 
instancia, sobre los jueces, que serán los encargados de matizar cómo deben interpretarse tanto las cláusulas como las posibles lagunas contractuales, y cuáles serán los efectos derivados de las mismas. ${ }^{69}$ A título ejemplificativo, podemos citar las excepciones referentes a la ineficacia o invalidez contractual donde tratándose de contratos inteligentes, "aun cuando podamos determinar algo sencillo como la mayoría de edad de las partes, no lo será tanto comprobar su capacidad de forma completa y, difícilmente, ver si el consentimiento está viciado ${ }^{70}$ en la medida en que entren en juego factores ajenos. Tampoco el objeto y la causa, en tanto estén ocultos y no pueda determinarse su licitud o su realidad (negocios simulados, objetos fuera de comercio, servicios imposibles...). Por tanto, la nulidad o anulabilidad ${ }^{71}$ de los contratos queda comprometida o es imposible". 72

Y la irrevocabilidad de las relaciones contractuales formalizadas en sistemas descentralizados, en virtud de la cual, una vez que un contrato inteligente ha sido válidamente perfeccionado no hay forma de interrumpir la ejecución de la transacción. Mientras que en los entornos centralizados existe la posibilidad de acudir a la persona o ente que controla el sistema para que detenga la ejecución, si alguna de las partes así lo ha decido, en la cadena de bloques no hay entidad encargada de esta función contra la que dirigirse, y por tanto, resulta imposible paralizarla o suspenderla. Y ello porque las organizaciones que desarrollan el software de la cadena de bloques no tienen poder sobre los nodos que validan las transacciones. Incluso si un tribunal ordenara a esos desarrolladores que emitieran una actualización que detuviera un contrato inteligente inserto en una cadena de bloques pública, como la de Bitcoin o Ethereum, los mineros no tendrían obligación de adoptarlo ni el tribunal forma de hacer cumplir su orden. $^{73}$

\section{III. ¿ES POSIBLE ENCUADRAR LOS CONTRATOS AUTOEJECUTABLES EN EL RÉGIMEN JURÍDICO QUE RESULTA DE APLICACIÓN A LOS CONTRATOS TRADICIONALES?: EL PROCESO DE FORMACIÓN}

Para poder responder a este interrogante resulta elemental clarificar si un contrato inteligente es un contrato propiamente dicho, y a su vez encuadrable en alguna de las categorías jurídicas existentes, o susceptible de constituir una nueva, o por el contrario debe excluirse del ámbito contractual. Por tanto, el punto de partida de dicha cuestión debe ser el ámbito legal, donde de un lado, la palabra "contrato" es notoriamente concebida como un "acuerdo de voluntades -se entiende: de dos o más seres humanos- que genera obligaciones jurídicamente vinculantes entre sus partes". Y de otro, "implica 
una serie de connotaciones que se quieren observar (la idea de autonomía o regulación por uno mismo de sus intereses, la idea de que esa autorregulación resulta de un acuerdo de voluntades de dos o más sujetos, la idea de coactividad o carácter vinculante de lo acordado) (...). (Lo cual) (...) se logra de dos formas: (...) mediante el seguimiento voluntario por las partes de una regulación pactada o a la que se han sometido por acuerdo; y (...) mediante los instrumentos de coerción jurídica (es decir, mediante los tribunales de justicia y los procedimientos de ejecución forzosa)" ${ }^{74}$

Respecto a la aplicación de estos principios a los contratos inteligentes, "la doctrina se ha posicionado fundamentalmente en dos posturas, los que niegan naturaleza contractual por sí misma a estos programas, considerando que son un mero instrumento para ejecutar de forma automática determinadas prestaciones de un acuerdo recogido en otro soporte, y los que por el contrario consideran que las cláusulas que deben auto-ejecutarse, no pueden desconectarse del acuerdo de voluntades que les da sentido, y que los smart contract son una variedad del contrato tradicional, caracterizado por la existencia de cláusulas autoejecutables". ${ }^{75}$

Dentro de la primera y minoritaria, se sitúan aquellos juristas que defienden que no es posible afirmar que "estamos ante una nueva categoría jurídica (...), porque un contrato inteligente (...) no es tanto una entidad jurídica como una entidad informática, un fragmento de programación, un mecanismo". ${ }^{76}$ En concreto, se visualizan como un "conjunto de protocolos informáticos que permiten a un dispositivo procesarlos por sí mismo y ejecutarlos de forma autónoma, sin necesidad de intervención humana". ${ }^{77}$ Es decir, "algunos (...) entienden que, a pesar del nombre, los smart contract no tienen nada que ver con los contratos y que, en consecuencia, todo lo que esté más allá del código es mera explicación o comentario" ${ }^{78}$ A nuestro parecer, de forma errónea dichas manifestaciones se enfocan únicamente en el sentido técnico, por cuanto reducen su visión a la secuencia o comando de código, esto es, al hecho de que se trata de programas o aplicaciones informáticas que insertan cierta información en forma de instrucciones en una cadena de bloques y ejecutan la función previamente programada de manera automática.

En consonancia con este criterio, también podemos encontrar a quien entiende que más que contratos propiamente dichos, son herramientas destinadas a la negociación y/o conclusión automática de relaciones contractuales. ${ }^{79}$ El fundamento de esta opción reside en la diferenciación de una doble casuística: los casos donde todo el proceso de suscripción del contrato inteligente tiene lugar online; y los supuestos donde, con carácter 
previo, las partes alcanzan un acuerdo offline $\mathrm{u}$ "off-chain en cualquiera de las formas que admite el derecho (un acuerdo verbal o documentado por escrito, ya sea en forma privada o pública)". En estos últimos, el rol del smart contract queda reducido a una herramienta de ejecución, y en definitiva, "viene a ser algo que se añade a ese contrato para facilitar la efectividad ya sea de todo su contenido o sólo de alguna parte, de alguna cláusula en concreto" ${ }^{80}$ Bajo nuestra opinión, esta perspectiva también hace una interpretación limitada de la realidad, pues defiende que el contrato autoejecutable más que un contrato es una cláusula que contiene una forma particular de ejecución, lo cual, no nos parece correcto porque esa cláusula carecería por completo de entidad sin un contrato que le de sentido y sustento jurídico. Si bien, es cierto que la complejidad a nivel jurídico de estos supuestos se aprecia mucho menor porque "el consentimiento se entiende otorgado ya en el momento de efectuar el precontrato. Cuando las partes aceptan el contenido del acuerdo y lo vuelcan en el código están dando su consentimiento por adelantado a los futuros contratos que automáticamente se vayan a concluir". ${ }^{81}$

Y dentro de la segunda posición, que es la mayoritaria, se afirma que "no nos encontramos ante un nuevo tipo de contrato como son la compraventa, la permuta, el arrendamiento (...), etc. Es más bien una 'modalidad' contractual: un medio de formalizar y ejecutar el contrato sobre la base de una tecnología avanzada". ${ }^{82}$ En concreto se precisa que se trata de contratos en formato electrónico, con un matiz, y es que gozan de carácter ejecutable. ${ }^{83}$ A este respecto, resulta que la noción legal que se ofrece de contrato electrónico lo contempla como "todo contrato en el que la oferta y la aceptación se transmiten por medio de equipos electrónicos de tratamiento y almacenamiento de datos, conectados a una red de telecomunicaciones" ${ }^{84}$

Además, hay que tener en cuenta ciertas particularidades que diferencian los contratos electrónicos de los tradicionales, las cuales "derivan fundamentalmente del mecanismo electrónico que se utiliza en el contrato, y residen básicamente: en su fase de formación; en el modo de prestar el consentimiento; en su caso, en la realización de las prestaciones; y en su prueba, siendo similares el resto de elementos esenciales". En base a estas consideraciones, a los contratos inteligentes les resultaría de aplicación "la normativa general de los negocios jurídicos y contratos, (...) la que regula la contratación electrónica y (...) la relativa a los servicios de la información (...), con las pertinentes adaptaciones" ${ }^{85}$ Pues bien, dentro de este marco contextual, se aprecia que con los contratos autoejecutables "nos encontramos ante una nueva estructura contractual de un tipo de contrato ya conocido con capacidad de garantizar el pleno y efectivo cumplimiento del principio 
pacta sunt servanda en términos cuasi absolutos mediante la auto ejecución ajena a las partes, y que no ve modificada su naturaleza jurídica por estar redactado en lenguaje código (...) e inserto en una cadena de bloques" ${ }^{86}$ No obstante, hay que matizar que esta figura "aporta novedades sustanciales respecto a otras modalidades de contratación electrónica por medio digitales a distancia; se trata de una modalidad singular de negociación telemática o cibernética", ${ }^{87}$ tal y como hemos visto al analizar su funcionamiento.

En suma, a priori, nos decantamos porque el segundo criterio es el más acertado ya que la finalidad intrínseca de los smart contracts es asegurar que se realice de forma efectiva la operación transaccional que constituye su objeto, de acuerdo al contenido pactado, y en este sentido, indudablemente se están generando expectativas de carácter jurídico. Si bien es cierto, que los medios utilizados para alcanzar dicho fin son diferentes, pues la verificación del cumplimiento de las prestaciones no depende de acciones humanas sino de un programa informático que realiza esa tarea de forma automatizada. A este respecto, vamos a centrarnos en los casos más complejos, donde todas las fases del proceso de formación del contrato inteligente se desarrollan en la Red y resulta fundamental analizar las posibles diferencias que puedan existir respecto a los tradicionales. Y ello, a los efectos de precisar si se cumplen en cada una de esas etapas los requisitos necesarios para afirmar que los contratos autoejecutables son contratos desde una perspectiva jurídica, y poder así ratificar o por el contrario modificar nuestro parecer.

\section{FASE DE EMISIÓN DE LA OFERTA CONTRACTUAL}

Como sabemos, todo proceso contractual se inicia con la emisión de una oferta dirigida a un cierto destinatario cuya finalidad es la de materializarla en un contrato, y en el caso concreto del ámbito digital, quién ofrece actividades de contratación electrónica (como puede ser la suscripción de un contrato inteligente) recibe el nombre de oferente o prestador de servicios de la sociedad de la información. Sobre dicha oferta existen ciertos requisitos a satisfacer por el oferente, y es que "legalmente tendrá la obligación de poner a disposición del destinatario, antes de iniciar el procedimiento de contratación y mediante técnicas adecuadas al medio de comunicación utilizado, de forma permanente, fácil y gratuita, información clara, comprensible e inequívoca sobre los siguientes extremos:

a) Los distintos trámites que deben seguirse para celebrar el contrato.

b) Si el prestador va a archivar el documento electrónico en que se formalice el contrato y si este va a ser accesible.

Revista de Estudios Jurídicos, UJAEN, España |AÑO 2021 NUM. 21, e6756 | ISSN 1576-124X 
c) Los medios técnicos que pone a su disposición para identificar y corregir errores en la introducción de los datos, y

d) La lengua o lenguas en que podrá formalizarse el contrato". 88

A lo anterior, la doctrina ${ }^{89}$ añade otras condiciones que ha de reunir la oferta, cuales son:

i) Que exista intención de obligarse por parte del oferente, cuestión que se constata además de con la identificación del mismo, con una declaración fehaciente y expresa de vinculación con lo que anuncia, sin más límites que la concreción del periodo de tiempo de validez de la oferta, o del número de ofertas disponibles.

ii) Que incluya la identificación del destinatario de la oferta, pues, aquella que se hace de forma genérica es considerada como mera invitación a la contratación.

iii) Que contenga información sobre las cuestiones más importantes del contrato, esto es, los elementos esenciales del mismo (consentimiento, objeto y causa) $;^{90}$ y las particularidades de la relación: identificación y características del objeto, precio, medios de pago, gastos e impuestos, vías de ejecución...

iv) Y que revista carácter definitivo, en el sentido de que no es admisible que el oferente se reserve la posibilidad de autorizar o rechazar la relación contractual después de que la oferta sea aceptada. Cuestión que dista del derecho a la revocación que asiste al oferente hasta el momento en que la oferta es aceptada, pues en base al principio de buena fe quien emite una oferta no puede revocarla ignorando su aceptación por el destinatario de forma dolosa, porque desde entonces el contrato quedó perfeccionado. ${ }^{91}$

\section{FASE DE ACEPTACIÓN DE LA OFERTA CONTRACTUAL O PERFECCIONAMIENTO DEL CONTRATO}

Habiéndose emitido válidamente una oferta, llega el momento de aceptarla, esto es, de perfeccionar el contrato, y aun tratándose de smart contracts la intervención humana sigue teniendo relevancia porque se va a entender que aquello sucede tras la prestación del consentimiento, que se produce en el momento en que las partes realizan las tareas previamente determinadas y programadas. En este sentido, son de aplicación los principios más elementales que sustentan el proceso de formación contractual, cuales son:

De un lado, el principio de autonomía de la voluntad, en virtud del cual los contratantes pueden incluir en el contrato todas las cláusulas o estipulaciones 
que consideren oportuno, siempre que no contravengan la legalidad, el orden público y la moral. ${ }^{92}$

Y de otro lado, el principio de libertad de forma, según el cual "los contratos serán obligatorios, cualquiera que sea la forma en que se hayan celebrado, siempre que en ellos concurran las condiciones esenciales para su validez". ${ }^{93}$ $\mathrm{O}$ sea, independientemente de que un contrato se formalice vía oral o escrita, y dentro de esta última en formato físico o electrónico, va a ser de obligatorio acatamiento para las partes, pues en cualquiera de los casos se produce un acuerdo de voluntades tendente a formalizar una relación que va a desplegar efectos jurídicos. ${ }^{94}$ Así, respecto a los supuestos en los que se emplee la forma digital, como sucede con los contratos inteligentes, se afirma que la implementación de los elementos esenciales del contrato puede tener lugar mediante el código informático, de la siguiente forma:

"Partiendo del consentimiento, no cabe dudar de que las partes pueden otorgar el mismo a través de medios electrónicos tales como la firma digital, ${ }^{95}$ que además de permitir verificar la identidad de las partes, también hace el mensaje difícilmente manipulable y accesible a terceros. Así la aceptación por las partes, (...) se manifestaría mediante la inserción de la firma digital en el programa, dando lugar al consentimiento". ${ }^{96}$ En este caso, con la firma electrónica de las partes se entiende emitido el consentimiento por aceptación expresa, es decir, por tratarse de un acto expreso o concluyente que indica el deseo de vinculación. Otra forma de este tipo de aceptación es la que tiene lugar con los llamados clickwrap agreements, que "constituyen un modo de contratar en el que se exige aceptación expresa de las condiciones y términos de un sitio web antes de concluir la contratación. Esta aceptación expresa suele llevarse a cabo por la acción de 'clickar' en el botón de 'acepto' o similar. A partir de dicho momento se entiende perfeccionado el contrato y surgen los vínculos entre las partes" ${ }^{97}$ Pero también cabe la aceptación tácita, que se produce a través de actos que no siendo expresos ni concluyentes, sí permiten presumir la anuencia del destinatario. A este respecto destaca el denominado browse wrapping, en virtud del cual el consentimiento se deduce del hecho de seguir navegando en un sitio web después de que este haya avisado de la existencia de una serie de términos y condiciones que se encuentran a disposición de los usuarios para su consulta. Un ejemplo, lo constituyen las conocidas cookies, cuya aceptación implica el conocimiento de los términos contractuales del sitio web que se visita. ${ }^{98}$ No obstante lo anterior, hay que tener presente que "en ningún caso la falta de respuesta a la oferta de contratación podrá considerarse como aceptación". ${ }^{99}$ En cualquiera de los casos, sobre el oferente pesa otra obligación, que es la de confirmar que ha 
recibido la aceptación de la otra parte, ya sea a través de un acuse de recibo o, del envío de la confirmación de dicha aceptación por medio fehaciente. ${ }^{100}$

En otro orden, aunque siguiendo en el ámbito del consentimiento, resulta que además de las formas de emitirlo, también son de aplicación a los contratos inteligentes los vicios que pueden provocar que estos sean nulos de pleno derecho. ${ }^{101}$ En concreto, el supuesto que puede concurrir con mayor facilidad es el del error propio, ${ }^{102}$ por cuanto al redactarse en lenguaje código existe la posibilidad de introducir en ellos algún elemento que difiera de lo realmente pretendido. Para tratar de evitar estas situaciones, especialmente si los contratantes no son especialistas en materia informática, sería recomendable generar el smart contract a través de plataformas que utilizan nuestro lenguaje y después traducen al código, o de emplear los ya referidos contratos ricardianos. ${ }^{103}$ Otra opción, podría ser la de "prever en los contratos herramientas que permitan anular el acuerdo, pausarlo o cancelarlo", ${ }^{104}$ si bien, en principio ello resulta complicado porque, como ya hemos señalado anteriormente, cuando un contrato inteligente se inserta en una blockchain no cabe su modificación por el carácter inmutable del que goza esta red. En este sentido existen criterios dispares, pues podemos encontrar a quién sostiene que la "nulidad o anulabilidad de los contratos queda comprometida o es imposible". ${ }^{105}$ Pero también, a quién defiende que "técnicamente es posible (...) flexibilizar la configuración técnica del contrato para 'rectificar' si se detecta la incursión en un supuesto de nulidad" porque de lo contrario "si hay alguna incidencia, la única posibilidad de actuar será a posteriori con medidas restitutorias o resarcitorias". ${ }^{106}$ En nuestra opinión ello dependería de una evolución en el ámbito de la programación, esto es, si los expertos informáticos que han desarrollado esta tecnología incorporan tal posibilidad sería plenamente factible, porque la inmutabilidad permanece inalterada en la medida en que no se producen modificaciones en el contrato, sino que se añade a la ejecución automática la facultad de paralizarla por motivos justificados. Ahora bien, entendiendo que el consentimiento ha sido prestado válidamente, existen otras dos cuestiones a reseñar:

Por un lado, la del lugar donde se entiende celebrado el contrato, y sobre este un sector de la doctrina ${ }^{107}$ afirma que "un contrato autoejecutable sigue las reglas generales de cualquier contrato concertado por vía electrónica, ${ }^{108}$ por lo que a falta de pacto o de foro imperativo por protección del consumidor, se entenderá concertado (...) en el domicilio del oferente". Es decir, dicha regla se aplica salvo que se pacte expresamente un lugar de perfeccionamiento distinto, que será el que se tome en consideración, o de que uno de los contratantes sea 
un consumidor, en cuyo caso será el lugar donde tenga su residencia habitual. ${ }^{109}$ Por el contrario, existen otros autores que sostienen que esta regla no resulta de aplicación, en la medida en que un contrato inteligente almacenado en una cadena de bloques no está ubicado físicamente, ni se administra en ningún lugar físico específico, o sea, está en todas partes y en ninguna. ${ }^{110}$ Combinando ambos criterios, parece razonable defender que solo cuando no se pueda identificar a las partes ni por tanto conocer su ubicación a la hora de contratar, quedarán excluidas las condiciones generales citadas.

Y, por otro lado, la que se refiere a la prueba de los contratos inteligentes en caso de que las partes se vean inmersas en un procedimiento judicial o extrajudicial (mediación, arbitraje...). A este respecto, teniendo en cuenta que aquellos se encuentran redactados en lenguaje código, no puede suponerse que los profesionales del sector tengan conocimientos en materia informática. Por ello, es necesario que los contratantes dispongan de la traducción en soporte digital, la cual debe contar con la firma electrónica de cada uno de ellos para tener plena validez como prueba en un juicio. ${ }^{111} \mathrm{Si}$ bien, esto no debería ser una carga para los desarrolladores de esta tecnología, que deberán proporcionar una versión en lenguaje natural del contrato a las partes para obtener el consentimiento mutuo. ${ }^{112} \mathrm{Si}$ esta condición no se hubiese cumplido cabe otra posibilidad, en la que "la prueba documental se tendrá que acompañar de la pertinente pericial informática que transcriba a lenguaje humano (en soporte electrónico o no) el contenido del contrato". ${ }^{113}$

En segundo lugar, en lo referente al objeto del contrato, no existe fundamento jurídico alguno que lleve a sostener que un bien, servicio o derecho, independientemente de su naturaleza física o intangible, no pueda ostentar dicha condición. Las únicas exigencias al respecto indican que debe tratarse de "cosas que no están fuera del comercio de los hombres"; "servicios que no sean contrarios a las leyes o a las buenas costumbres" o que no sean imposibles; además de que la cuantía se encuentre "determinada en cuanto a su especie" o al menos sea determinable "sin necesidad de nuevo convenio entre los contratantes". ${ }^{114}$ Sobre ello, la doctrina recalca que la tecnología blockchain facilita el pseudoanonimato de sus usuarios, lo cual genera un riesgo de que el objeto del smart contract sea ilícito. ${ }^{115}$

Y, por último, en lo relativo a la causa del contrato, es imprescindible que se trate de una causa que existe, es lícita y veraz. En concreto, tratándose de "contratos onerosos se entiende por causa, para cada parte contratante, la prestación o promesa de una cosa o servicio por la otra parte; en los remuneratorios, el servicio o beneficio que se remunera, y en los de pura 
beneficencia, la mera liberalidad del bienhechor". ${ }^{116}$ Por ello, a nuestro parecer, nada obsta para interpretar que la causa de una obligación contractual contraída a través de medios electrónicos es igualmente válida, y no plantea controversia alguna. ${ }^{117}$

En suma, sobre la base de concebir los contratos autoejecutables como una modalidad de contratos electrónicos, y en la medida en que se pueda constatar la concurrencia de las condiciones que se promulgan para estos, apreciamos plena equivalencia con los contratos tradicionales en esta fase y por tanto nada impide aplicar su normativa reguladora para que desplieguen los correspondientes efectos jurídicos.

\section{FASE DE EJECUCIÓN: PAGOS ELECTRÓNICOS CON CRIPTOMONEDAS Y DINERO ELECTRÓNICO}

El rasgo distintivo más evidente que encontramos entre los contratos tradicionales y los inteligentes, y "que se propugna desde el lado de los tecnólogos informáticos como gran avance alternativo superador del Derecho" 118 radica en la fase de ejecución o conclusión. Y ello por cuanto, en esta última etapa del proceso de contratación la voluntad humana no tiene cabida, ya que el cumplimiento del acuerdo previamente perfeccionado, deviene automático por la facultad de autoejecución que caracteriza los smart contracts. Es decir, "a diferencia del contrato ordinario, una vez fijadas las reglas de ejecución, (...) el mecanismo de ejecución no dependerá de la voluntad de las partes, sino de un programa que actuará automáticamente cuando identifique las reglas de ejecución. Para que esta respuesta automática sea posible es necesario poder programar un pago que no dependa de una orden posterior ${ }^{119}$ a la ejecución de parte y es por esto es lo que la mayor parte de los Smart contract terminan apoyándose en la tecnología de bloques y ejecutando el pago en criptomonedas o monedas virtuales ${ }^{120}$ como el bitcoin pero, en realidad, cualquier otro formato tecnológico sería igualmente admisible y funcional si cumpliera con las características citadas". ${ }^{121}$ De este pronunciamiento inferimos dos ideas:

El perfecto encuadre ${ }^{122}$ de la automaticidad de los contratos inteligentes en el ámbito del dinero electrónico, ${ }^{123}$ en la medida en que aporta "un medio de pago con estabilidad (la misma que la moneda real que representa), convertibilidad garantizada, garantía de solvencia razonablemente asegurada por la autoridad de supervisión financiera, reconocimiento legal y adaptación al medio electrónico por su propia naturaleza". No obstante, consideramos de interés matizar que "el principal motivo por el que las plataformas de 
contratación automática no siempre usan dinero digital, es por la escasez de oferta comercial. (...) A día de hoy, cuesta articular un sistema de pago automatizado en euros digitales porque las entidades de pago, mayormente entidades de crédito, siguen dando prioridad a los instrumentos de pago a distancia (...) Mientras tanto, las criptomonedas de emisión privada han ido ocupando el hueco que el sistema legal no ha querido o no ha sabido llenar". ${ }^{124}$

$\mathrm{Y}$ en consonancia con el juicio expuesto, la segunda idea reside en la promulgación de las criptodivisas como el instrumento de pago ideal para la conclusión de los contratos inteligentes de carácter oneroso por cuanto: en primer lugar, su creación "nos ha permitido disponer de un dinero digital, susceptible de tráfico en un entorno puramente digital (con control de su emisión (...) sin necesidad de un tercero intermediario) y además susceptible de programación (...). Y, en segundo lugar, porque (...) el contrato o la relación de intercambio o cooperación económica no sólo digitalizada sino programada en forma de código autoejecutable (...) se incorpora e implementa en un registro distribuido, en red, que reside a la vez en miles de ordenadores, (...) protegido por una técnica criptográfica que lo hace inmodificable e irreversible". ${ }^{125}$

Ahora bien, al margen de lo anterior, es necesario analizar la concurrencia de ciertos presupuestos legales, de la misma forma que hemos hecho con las fases previas de emisión de la oferta contractual y perfeccionamiento del contrato. Con carácter general, se predica que la entrega de la cosa objeto del contrato conlleva ponerla en poder y posesión del comprador, ${ }^{126}$ distinguiéndose ciertas especialidades para cuando se trata de un bien mueble o de un bien incorporal. En el primer caso, se entiende realizada "por la entrega de las llaves del lugar o sitio donde se hallan almacenados o guardados"; y en el segundo, "por (...) el hecho de poner en poder del comprador los títulos de pertenencia, o el uso que haga de su derecho". ${ }^{127}$ Si trasladamos esta teoría a los medios de pago electrónicos como las monedas virtuales y el dinero electrónico, resulta que por tratarse de bienes intangibles, nos encontramos en la segunda modalidad de entrega y, por cuanto no existe título alguno que acredite la pertenencia de estas, lo que se entrega es aquello que permite utilizarlas, esto es, sus claves criptográficas. ${ }^{128}$ Sentado lo anterior, en todo caso los pagos deben realizarse exactamente conforme a lo previsto por las partes en el momento de constituir la relación obligacional, y para ello se exige la satisfacción de los siguientes requisitos $^{129}$ :

Integridad, en virtud de la cual hay que entregar al completo la cosa o realizar la prestación que constituye el objeto contractual. 
Identidad, o sea, se debe entregar la cosa o realizar la prestación pactada y no otra diferente, independientemente de que la nueva sea igual, menor, mayor, de inferior o superior calidad... Asimismo, tratándose de deudas dinerarias se precisa entregar la especie pactada y sólo si esto no fuese posible, se admitiría la entrega en la moneda de curso legal.

Indivisibilidad, es decir, salvo que se haya pactado lo contrario, no cabe la realización de prestaciones parciales.

Y localización, esto es, el pago debe ejecutarse en el lugar que se haya designado expresamente. Si bien, a falta de pronunciamiento en tal sentido, si se trata de la entrega de una cosa, se entiende que ha de hacerse donde aquella estaba a la hora de constituir la obligación; y para el resto de los supuestos, se hará en el domicilio del deudor.

A nuestro parecer, estas condiciones son plenamente aplicables a los contratos autoejecutables, pues al optar por esta opción las partes están decidiendo no solo que el pago estará automatizado según lo programado, sino también que la ejecución de aquel sea inevitable. De esta forma, si por ejemplo el precio estipulado de la operación es de 2 Bitcoin (no cabe entregar 1 Bitcoin, $3 € \mathrm{o} 5 \$$ ), solo cuando estos hayan sido transferidos por el comprador al servidor del smart contract se producirá la extinción de la obligación de pago, la liberación del deudor y automáticamente las pretensiones del acreedor quedarán satisfechas.

Además de las condiciones generales expuestas, existen otros supuestos de carácter más específico que la doctrina ${ }^{130}$ analiza en el marco de los smart contracts, y que resulta interesante mencionar, como son:

Los pagos realizados por terceros, ${ }^{131}$ en la medida en que un pago puede satisfacerse por cualquier persona distinta al deudor, con o sin conocimiento de este e independientemente de que el pagador ejerza después su facultad de reclamación o repetición contra aquel o no. A este respecto, aún en el supuesto de que el pago sea único, solo permite al acreedor subrogarse en los derechos del deudor si actuó bajo el conocimiento de este. En el ámbito de los smart contracts esta posibilidad es admisible aunque complicada por la automatización de las instrucciones que lo conforman, y también parece irracional por cuanto podría derivar en un pago duplicado, el que procede del deudor y el que genera el tercero.

Los pagos hechos a un acreedor que aparentemente está en "posesión del crédito", ${ }^{132}$ cuyo encaje en los contratos inteligentes también se aprecia difícil pues el software que los sustenta se encarga de verificar de forma objetiva, a 
través de la cadena de bloques, si efectivamente las criptomonedas pertenecen a quién actúa como comprador o ya han sido consumidas por este. De manera que en la primera hipótesis aceptará la operación y en la segunda la rechazará.

Los pagos subrogados, como la cesión de bienes ${ }^{133}$ o la dación en pago, ${ }^{134}$ directamente parecen no tener encuadre en los contratos autoejecutables, ya que dada la inmutabilidad que los caracteriza, una vez formalizados solo cabe su cumplimiento de la forma previamente dispuesta, y por tanto, para una ejecución alternativa sería necesaria la formalización de un segundo acuerdo entre los contratantes que contemplase el cambio pretendido.

Y la imputación de pagos, ${ }^{135}$ la cual, al igual que en los casos anteriores tampoco resulta fácil de incardinar en los contratos inteligentes, pues en la fase de formación de estos quedan fijadas tanto las partes como el objeto contractual (pretensión y pago), no cabiendo interpretación o modulación posterior que permita alterar lo programado.

\section{CONCLUSIÓN}

Desde hace algunas décadas, nos encontramos inmersos en el seno de la era digital, caracterizada por un desarrollo evolutivo continuo originado por los incesantes avances acaecidos en el ámbito de las nuevas tecnologías. Y es que el impacto que esta realidad ha tenido en la sociedad es difícil de evaluar porque, además de influenciar nuestro comportamiento social, repercute en diversos sectores como son el económico, educativo, jurídico, político...

Las mayores novedades se han producido en los últimos años, y dentro de ellas destacamos la creación de cadena de bloques o blockchain, basada en la tecnología de registro distribuido. Entre los usos o aplicaciones más conocidas que se han dado a este software encontramos la creación de criptomonedas y la constitución de contratos inteligentes. En el presente trabajo, nos hemos centrado en abordar estos últimos porque respecto a ellos han surgido distintas controversias en el entorno jurídico, las cuales redundan en la necesidad de catalogar su naturaleza, para determinar si precisan una normativa específica que los regule o no. Tras un amplio análisis doctrinal se ha considerado que su reglamentación no resulta necesaria porque no integran una nueva categoría contractual, sino que se erigen como una modalidad de contratos electrónicos cuyas especialidades son:

El desarrollo de sus estipulaciones en lenguaje código;

Y el carácter automático de su fase de ejecución, que implica poder utilizar instrumentos de pago electrónicos que no requieren autorización posterior 
ni acreditación de identidad, además de eliminar la necesidad de acudir a terceros intermediarios que insten la ejecución forzosa porque no cabe el incumplimiento contractual.

En base a estas particularidades, a los contratos inteligentes les resulta de aplicación el régimen jurídico de los contratos tradicionales u ordinarios, de manera que serán válidos dentro del ordenamiento jurídico español y desplegarán los correspondientes efectos siempre y cuando cumplan lo dispuesto en:

El Código Civil, respecto al proceso de formación contractual (contar con el consentimiento de los contratantes, recaer sobre un objeto cierto, y concurrir una causa real y lícita en las obligaciones contraídas);

Y en el resto de normas, reguladoras de los casos de carácter específico, tales como las disposiciones vigentes en materia de consumidores, aplicables si alguno de los contratantes ostenta tal condición.

\section{BIBLIOGRAFÍA}

ALBALADEJO GARCÍA, M. (1989), Derecho civil II, vol. 1, 8ª Edición, Bosch, Barcelona.

ANGUIANO JIMÉNEZ, J. M. (2018), 'Smart Contracts'. Introducción al 'contractware', 'Innovación \& Tendencias - Sector legal' de Wolters Kluwer, Garrigues Digital.

ANGUIANO JIMÉNEZ, J. M. (2018), "Blockchain: Fundamentos y perspectiva jurídica. De la confianza al consenso", Diario La Ley, $\mathrm{n}^{\circ} 18$, Sección Ciberderecho, Wolters Kluwer.

ANTONOPOUlOS, A. M. (2017), Mastering Bitcoin: Unlocking Digital Cryptocurrencies, O’Reilly Media, $2^{\text {a Edición. }}$

BERROCAL LANZAROT, A. I. (2012), "El dinero electrónico y las entidades de dinero electrónico tras las reformas operadas por la ley 21/2011, de 26 de julio y por el real decreto 778/2012, de 4 de mayo", Revista de la contratación electrónica, $\mathrm{n}^{\circ} 118$.

BOAR, A. (2018), "Blockchain, bitcoin y criptomonedas. Bases conceptuales y aplicaciones prácticas. Primera parte: Artículos: Efectos de la tecnología blockchain en el sector financiero y empresarial", Revista de Contabilidad y Dirección, vol. 27.

BOURQUE, S. y FUNG LING TSUI, S. (2014), “A lawyer's introduction to smart contract”, Scientia Nobilitat Reviewed Legal Studies, $\mathrm{n}^{\circ} 201$. 
CARRASCO PERERA, A., CORDERO LOBATO, E., MARÍN LÓPEZ, M. J. (2016), Lecciones de Derecho Civil. Derecho de obligaciones y contratos en general, $2^{\mathrm{a}}$ Edición, Tecnos.

CARRACEDO GARNATEO, P. y GUAITA MARTÍNEZ, J. M. (2019), "El fenómeno de las criptomonedas", Monografías. Las criptomonedas: Digitalización del dinero 2.0., Editorial Aranzadi, S.A.U, BIB 2019\1754.

CASANUEVA CAÑETE, D. y LÓPEZ DE LA CRUZ, N. (2018), "El concepto de criptomoneda y breves consideraciones en torno a su tributación", VI Encuentro de Derecho Financiero y Tributario "Tendencias y retos del Derecho Financiero y Tributario", Instituto de Estudios Fiscales, Madrid.

CLACK, C. D., BAKSHI, V. A., BRAINE, L. (2016), "Smart Contract Templates: foundations, design landscape and research directions".

CIACCAGLIA, M. (2019), "Blockchain y smart contracts entre la normativa europea y el código civil español”, Revista Aranzadi de Derecho y Nuevas Tecnologías, $\mathrm{n}^{\circ}$ 51, parte Estudios Jurídicos, Editorial Aranzadi, S.A.U., Cizur Menor.

CUCCURU, P. (2017), "Blockchain ed automatizacione contrattuale. Riflessioni sugli smart contract", La Nuova giurisprudenza civile commentata, vol. $33, \mathrm{n}^{\mathrm{o}} 1$.

DE CASTRO Y BRAVO, F. (1985), El negocio jurídico, Civitas, S.A., Madrid.

DÍAZ DÍAZ, E. (2019), “Una aplicación jurídica del 'Blockchain': los 'Smart Contracts", Revista Aranzadi de Derecho y Nuevas Tecnologías, $\mathrm{n}^{\circ}$ 50, Editorial Aranzadi, S.A.U., BIB 2019/7005.

DÍEZ-PICAZO y PONCE DE LEÓN, L. (1996), Fundamentos del Derecho Civil Patrimonial, Tomo II, Civitas, Madrid.

DÍEZ-PICAZO y PONCE DE LEÓN, L. (2007), Fundamentos del Derecho Civil Patrimonial I, 6 a Edición, Civitas, Madrid.

ECHEBARRÍA SÁENZ, M. (2017), "Contratos autoejecutables (smart contracts) y pagos con tecnología blockchain", Revista de Estudios Europeos, $\mathrm{n}^{\circ} 70$.

FELIU REY, J. (2018), "Smart Contract: Concepto, ecosistema y principales cuestiones de Derecho privado", La Ley Mercantil, n 47.

FERTSYAK, I. (2020), "Contratos inteligentes: Análisis jurídico desde el marco legal español”, Revista Electrónica del Departamento de Derecho de la Universidad de la Rioja, $\mathrm{n}^{\circ}$ 18, https://doi.org/10.18172/redur.4898.

FOZ GIRALT, X., MATINERO TOR, J., MORALES CÁCERES, J. R., CARRASCOSA COBOS, C. (2017),Aspectos legales de los ICOS, Smart 
Contracts y DAO. In Blockchain: La revolución industrial de Internet, Gestión 2000, Barcelona.

GARCÍA MEXÍA, P. (Dir.), ARANDA BRIONES, B. (Coord.) y ALCAIDE SOLER, F. (Coord.) (2018), Criptoderecho. La regulación de Blockchain, LA LEY, Wolters Kluwer.

GÓMEZ REQUENA, J. A. (2018), “Se van a solucionar los problemas de asimetrías de información en los precios de transferencia con la aplicación de la tecnología blockchain?", VI Encuentro de Derecho Financiero y Tributario "Tendencias y retos del Derecho Financiero y Tributario", Instituto de Estudios Fiscales, Madrid.

GONZÁLEZ-MENESES ROBLES, M. (2017), Entender Blockchain. Una introducción a la Tecnología de Registro Distribuido, Aranzadi, Pamplona.

GONZÁLEZ-MENESES ROBLES, M. (2020), “'Smart contracts”: ¿hacia una economía sin derecho contractual?", Aranzadi digital, $\mathrm{n}^{\circ}$ 1, Editorial Aranzadi, S.A.U., BIB 2020/12401.

GORJÓN, S. (enero de 2014), Nota informativa del Banco de España sobre las Divisas o Monedas Virtual: El caso de Bitcoin.

HERNÁNDEZ MARTÍNEZ, A. (2020), “Aplicación del 'smart contract' a la transferencia de derechos federativos de jugadores de fútbol", Revista Aranzadi de Derecho de Deporte y Entretenimiento, $\mathrm{n}^{\circ}$ 66, Editorial Aranzadi, S.A.U, BIB 2020\8052.

IBÁÑEZ JIMÉNEZ, J. W. (2018), "Smart contract y notariado español: algunas claves orientadoras", La Ley Mercantil, n 48.

LACRUZ BERDEJO, J. L. (2011), Elementos de derecho civil, Tomo II: Derecho de obligaciones, $5^{\text {a }}$ Edición, Dykinson.

LEGERÉN-MOLINA, A. (2018), "Los contratos inteligentes en España. La disciplina de los smart contracts", Revista de Derecho Civil, vol. V, ${ }^{\circ} 2$ (abril-junio), Estudios.

MADRID PARRA, A (2018), "Dinero electrónico revisitado", Revista de Derecho Bancario y Bursátil, no 151, parte Artículos, BIB 2018/10809, Editorial Aranzadi, S.A.U., Cizur Menor.

MADRID PARRA, A. (2020), "Smart Contracts-Fintech: Reflexiones para el debate jurídico", Revista Aranzadi de Derecho y Nuevas Tecnologías, $\mathrm{n}^{\circ} 52$, Editorial Aranzadi, S.A.U., BIB 2020/9443.

MAKHDOOM, I., ABOLHASAN, M., ABBAS, H., \& NI, W. (2018), "Blockchain's adoption in IoT: The challenges, and a way forward", Journal of Network and Computer Applications, $\mathrm{n}^{\circ}$ 125, https://doi.org/10.1016/j.jn ca.2018.10.019. 
MILLÁN TEJEDOR, R.J. (2019), "Tecnología Blockchain. La cadena de bloques segura, inalterable, transparente... y disruptiva!", BIT, $\mathrm{n}^{\circ} 212$, COIT \& AEIT.

MOLINA PÉREZ-TOMÉ, S. (2019), "Los smart contracts no son contratos ni son inteligentes", LEGALTECH TOUR: TOUR 2 BLOCKCHAIN, LegalToday.

NAVAS NAVARRO, S. (2015), "Un mercado financiero floreciente: el del dinero virtual no regulado (especial atención a los BITCOINS)", Revista CESCO de Derecho de Consumo, $\mathrm{n}^{\circ} 13$.

O'SHIELDS, R. (2017), Smart contracts: Legal Agreements for the Blockchain, 21 North Carolina Banking Institute, 177.

OTERO MOREIRAS, I. (2019), "Análisis jurídico de los smart contract", LEGALTECH TOUR: TOUR 2 BLOCKCHAIN, LegalToday.

PARRONDO, L. (2018), "Blockchain, bitcoin y criptomonedas. Bases conceptuales y aplicaciones prácticas. Primera parte: Artículos: Tecnología blockchain, una nueva era para la empresa", Revista de Contabilidad y Dirección, vol. 27.

PEDREIRA MENÉNDEZ, J. (2018), "Consideraciones sobre la tributación y la calificación contable de las operaciones con moneda digital (Bitcoins) en las empresas", Revista Quincena Fiscal, ${ }^{\circ} 3$, parte Estudio, Editorial Aranzadi, S.A.U., Cizur Menor, BIB $2018 \backslash 5747$.

PEDREIRA MENÉNDEZ, J. (2018), "La contabilización y tributación de la moneda digital (Bitcoins)", VI Encuentro de Derecho Financiero y Tributario "Tendencias y retos del Derecho Financiero y Tributario", Instituto de Estudios Fiscales, Madrid.

PEDREIRA MENÉNDEZ, J. y ÁLVAREZ PÉREZ, B. (2020), "Las ICO como vía de financiación empresarial a través de tokens", Revista Quincena Fiscal, no 15-16, Editorial Aranzadi, S.A.U., BIB $2020 \backslash 35309$.

PRENAFETA RODRÍGUEZ, J. (2016), "Smart contracts: aproximación al concepto y problemática legal básica", Diario La Ley, nº 8824.

PUJALTE MÉNDEZ-LEITE, H. (2017), "La proliferación de las monedas virtuales en un entorno desregulado: su impacto en la fiscalidad", Revista de Fiscalidad Internacional y Negocios Transnacionales, $\mathrm{n}^{\circ}$ 6, parte Cuestiones prácticas, Editorial Aranzadi, S.A.U., Cizur Menor.

RASKIN, M. (2017), "The law and legality of smart contracts", Georgetown Law Technology Review, $\mathrm{n}^{\mathrm{o}}$ 304, https://doi.org/10.2139/ssrn.2842258.

RODRÍGUEZ, N. (2019), “¿Qué son los contratos ricardianos? Guía completa", 101 Blockchains. 
ROSERO-CORREA, L., MORALES-MORALES, M. y MORALESCARDOSO, S. (2020), "Registro de títulos académicos mediante una aplicación basada en Blockchain y Smart Contracts", Revista Cátedra, 3(2), https://doi.org/10.29166/catedra.v3i2.2200.

SÁNCHEZ CALERO, F. J. (2016), Curso de Derecho Civil II. Derecho de obligaciones, contratos y responsabilidad por hechos ilícitos, Edición $8^{\mathrm{a}}$, Tirant lo Blanch, Valencia.

SAVELYEV, A. (2016), "Contract Law 2.0: Smart Contracts as the Beginning of the End of Classic Contract Law", National Research University Higher School of Economics, https://doi.org/10.2139/ssrn.2885241.

SKLAROFF, J. M. (2017), "Smart Contracts and the Cost of Inflexibility", University of Pensilvania Law Review, vol. 166.

SUBIRANA, C. (2018), "Blockchain, bitcoin y criptomonedas. Bases conceptuales y aplicaciones prácticas. Primera parte: Artículos: Cómo la tecnología blockchain transformará las cadenas de suministro", Revista de Contabilidad y Dirección, vol. 27.

TAPSCOTT, D. y TAPSCOTT, A. (2016), Blockchain revolution: How the Technology Behind Bitcoin is changing money, business, and the world, Penguin Random House.

TUR FAÚNDEZ, C. (2018), Smart contracts. Análisis jurídico, Editorial Reus, Madrid.

VILALTA NICUESA, A. (2019), Smart legal contracts y blockchain: La contratación inteligente a través de la tecnología blockchain, Wolters Kluwer, Madrid.

VILLALBA SÁNCHEZ, A. (2019), "El principio de transparencia en la ejecución automatizada del contrato de trabajo: una aproximación jurídica a la tecnología ‘blockchain' y a la inteligencia artificial”, Revista Española de Derecho del Trabajo, $\mathrm{n}^{\circ}$ 224, Editorial Aranzadi, S.A.U., BIB $2019 \backslash 9021$.

WERBACH, K. y CORNELL, N. (2017), “Contracts Ex Machina”, Duke Law Journal, vol. 67.

NOTAS

1 Doctoranda del Programa de Doctorado en Derecho, área de Derecho Mercantil, de la Facultad de Ciencias Sociales y Jurídicas de la Universidad de Jaén. ORCID: 0000-0001-5101-2034. Email: acg00067@red.ujaen.es

2 Survey Report, September 2015, of WORLD ECONOMIC FORUM: Deep Shift Technology Tipping Points and Societal Impact, p. 24, enhttp://www3.weforum.org/docs/WEF_GAC15_T echnological_Tipping_Points_report_2015.pdf(consultado el 10 de mayo de 2021) 
3 Insight Report, May 2021, of WORLD ECONOMIC FORUM: Digital Assets, Distributed Ledger Technology and the Future of Capital Markets, p. 17, en http://www3.weforum.org/doc s/WEF_Digital_Assets_Distributed_Ledger_Technology_2021.pdf (consultado el 10 de mayo de 2021). En este documento literalmente se dispone que la DLT es "an immutable distributed database that governs the flow of data between decentralized participants", y los elementos que la integran son: "1. Distributed ledger and peer-to-peer network: data representing assets or transactions is replicated across each node on the network, ensuring resiliency and transparency. 2. Digital signatures and hash functions: strong encryption and anti-tampering measures guard against data being retroactively altered. 3. Consensus algorithms: a consensus mechanism authenticates the underlying data to ensure that all participants have the same view of the data, potentially eliminating the need for trusted intermediaries in a transaction. 4. Smart contracts: machine-executable code is automatically triggered to enforce contractual obligations under predefined circumstances".

4 ANGUIANO JIMÉNEZ, J. M. (2018), 'Smart Contracts'. Introducción al 'contractware', 'Innovación \& Tendencias - Sector legal' de Wolters Kluwer, Garrigues Digital, en https://www .garrigues.com/es_ES/noticia/smart-contracts-introduccion-al-contractware (consultado el 7 de mayo de 2021).

5 PEDREIRA MENÉNDEZ, J. y ÁLVAREZ PÉREZ, B. (2020), "Las ICO como vía de financiación empresarial a través de tokens", Revista Quincena Fiscal, n 15-16, Editorial Aranzadi, S.A.U., BIB 2020\35309, p. 2.

6 MILLÁN TEJEDOR, R. J. (2019), "Tecnología Blockchain. La cadena de bloques segura, inalterable, transparente... y disruptiva!", BIT, n 212, COIT \& AEIT, pp. 59, en https://www.co it.es/sites/default/files/archivobit/pdf/bit_212_tecnologia_ramon_millan.pdf (consultado el 12 de mayo de 2021). Otra definición la podemos encontrar en GORJÓN, S. (enero de 2014), Nota informativa del Banco de España sobre las Divisas o Monedas Virtual: El caso de Bitcoin, p. 2, donde se indica que es una "red de distribución Persona-a-Persona, a través de nodos interconectados (ordenadores) que representan al colectivo de usuarios".

7 ECHEBARRÍA SÁENZ, M. (2017), "Contratos autoejecutables (smart contracts) y pagos con tecnología blockchain”, Revista de Estudios Europeos, $\mathrm{n}^{\circ} 70$, p. 77, en http://uvadoc.uva.es/bitst ream/handle/10324/28434/Estudios-Europeos-2017-70-Contratos-electr\%c3\%b3nicos-autoeje cutables...\%2869-97\%29.pdf?sequence=1\&isAllowed=y (consultado el 11 de abril de 2021). CARRACEDO GARNATEO, P. y GUAITA MARTÍNEZ, J. M. (2019), "El fenómeno de las criptomonedas", Monografías. Las criptomonedas: Digitalización del dinero 2.0., Editorial Aranzadi, S.A.U, BIB 2019 \1754, p. 5, referenciando a ANTONOPOULOS, A. M. (2017),

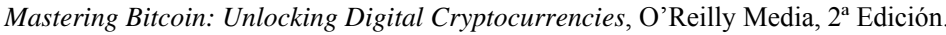

9 PEDREIRA MENÉNDEZ, J. (2018), “Consideraciones sobre la tributación y la calificación contable de las operaciones con moneda digital (Bitcoins) en las empresas", Revista Quincena Fiscal, n 3, parte Estudio, Editorial Aranzadi, S.A.U., Cizur Menor, BIB 2018\5747, p. 2.

10 HERNÁNDEZ MARTÍNEZ, A. (2020), “Aplicación del 'smart contract' a la transferencia de derechos federativos de jugadores de fútbol", Revista Aranzadi de Derecho de Deporte y Entretenimiento, $\mathrm{n}^{\circ}$ 66, Editorial Aranzadi, S.A.U, BIB 2020 $\backslash 8052$, p. 14.Asimismo, otra definición que nos resulta relevante es la que se ofrece en PEDREIRA MENÉNDEZ, J. y ÁLVAREZ PÉREZ, B. (2020), p. 4, nota al pie 7, referenciando a GONZÁLEZ-MENESES ROBLES, M. (2017), Entender Blockchain. Una introducción a la Tecnología de Registro Distribuido, Aranzadi, Pamplona, donde se establece que "es un registro de transacciones, como lo es un tradicional libro de contabilidad, solo que diseñado para almacenar los datos a través de internet, de modo que cualquier usuario con conexión a la red puede introducir y registrar operaciones que acaban uniéndose y creando una cadena, y que a diferencia de las bases de datos tradicionales permite el intercambio entre iguales y sin intermediarios $(P 2 P)$, conformando un libro mayor 'distribuido' o descentralizado".

11 A título ejemplificativo destacamos los pronunciamientos de GÓMEZ REQUENA, J. A. (2018), “Se van a solucionar los problemas de asimetrías de información en los precios de transferencia con la aplicación de la tecnología blockchain?", VI Encuentro de Derecho Financiero y Tributario "Tendencias y retos del Derecho Financiero y Tributario", Instituto de Estudios Fiscales, Madrid, p. 116. 
CONCEPTUALIZACIÓN DE LOS CONTRATOS INTELIGENTES O AUTOEJECUTABLES BASADOS EN LA TECNOLOGÍA... Adoración CASTELLANO GARCÍA

34

12 Según DÍAZ DÍAZ, E. (2019), “Una aplicación jurídica del 'Blockchain': los ‘Smart Contracts", Revista Aranzadi de Derecho y Nuevas Tecnologías, no 50, Editorial Aranzadi, S.A.U., BIB 2019/7005, p. 4, "el hash es el número de identificación del bloque. Se trata de un número único e irrepetible, de igual extensión con independencia del contenido. Cada uno de los bloques tiene el suyo propio. La tercera tiene el hash del bloque anterior. Por tanto, cada bloque queda conectado con su predecesor y sucesor". Asimismo, desde una óptica finalista se pronuncia MADRID PARRA, A. (2020), "Smart Contracts-Fintech: Reflexiones para el debate jurídico", Revista Aranzadi de Derecho y Nuevas Tecnologías, n 52, Editorial Aranzadi, S.A.U., BIB 2020/9443, pp.10, disponiendo que "es el procedimiento por el que se garantiza la integridad del contenido tanto de cada una de las transacciones como de la cadena que estas forman".

13 PEDREIRA MENÉNDEZ y ÁLVAREZ PÉREZ, (2020), p. 3.

14 MAKHDOOM, I., ABOLHASAN, M., ABBAS, H., \& NI, W. (2018), "Blockchain's adoption in IoT: The challenges, and a way forward", Journal of Network and Computer Applications, $\mathrm{n}^{\circ}$ 125, p. 255, https://doi.org/10.1016/J.JNCA.2018.10.019 (consultado el 15 de mayo de 2021).

15 CIACCAGLIA, M. (2019), "Blockchain y smart contracts entre la normativa europea y el código civil español”, Revista Aranzadi de Derecho y Nuevas Tecnologías, $\mathrm{n}^{\circ}$ 51, parte Estudios Jurídicos, Editorial Aranzadi, S.A.U., Cizur Menor, p. 4. Además, podemos precisar que de conformidad con lo dispuesto en el apartado 32 del Anexo II "Definiciones" de la Ley 9/2014, de 9 de mayo, General de Telecomunicaciones. BOE n 114/2014, es aquella "que se utiliza, en su totalidad o principalmente, para la prestación de servicios de comunicaciones electrónicas disponibles para el público".

16 GÓMEZ REQUENA, (2018), p. 116. Legalmente y a sensu contrario con la definición recogida en la nota anterior (14), se entiende que una red o base datos cerrada es aquella en la que el acceso a los servicios prestados se encuentra restringido a ciertos sujetos.

17 PARRONDO, L. (2018), "Blockchain, bitcoin y criptomonedas. Bases conceptuales y aplicaciones prácticas. Primera parte: Artículos: Tecnología blockchain, una nueva era para la empresa", Revista de Contabilidad y Dirección, vol. 27, p. 17.

18 BOAR, A. (2018), "Blockchain, bitcoin y criptomonedas. Bases conceptuales y aplicaciones prácticas. Primera parte: Artículos: Efectos de la tecnología blockchain en el sector financiero y empresarial", Revista de Contabilidad y Dirección, vol. 27, p. 35.

19 HERNÁNDEZ MARTÍNEZ, (2020), p. 27.

20 PEDREIRA MENÉNDEZ, J. (2018), "La contabilización y tributación de la moneda digital (Bitcoins)", VI Encuentro de Derecho Financiero y Tributario "Tendencias y retos del Derecho Financiero y Tributario”, Instituto de Estudios Fiscales, Madrid, p. 138.

21 Para mayor ahondamiento en este proceso aconsejamos consultar el estudio realizado en NAVAS NAVARRO, S. (2015), "Un mercado financiero floreciente: el del dinero virtual no regulado (especial atención a los BITCOINS)", Revista CESCO de Derecho de Consumo, $\mathrm{n}^{\circ}$ 13 , pp. $95-100$.

22 GORJÓN, (2014), p. 6.

23 SUBIRANA, C. (2018), "Blockchain, bitcoin y criptomonedas. Bases conceptuales y aplicaciones prácticas. Primera parte: Artículos: Cómo la tecnología blockchain transformará las cadenas de suministro", Revista de Contabilidad y Dirección, vol. 27, p. 51. Y para mayor ahondamiento se aconseja consultar la doctrina referenciada en CIACCAGLIA, M. (2019), p. 3 , nota al pie 15 .

24 ROSERO-CORREA, L., MORALES-MORALES, M. y MORALES-CARDOSO, S. (2020), "Registro de títulos académicos mediante una aplicación basada en Blockchain y Smart Contracts", Revista Cátedra, 3(2), p. 82, https://doi.org/10.29166/10.29166/catedra.v3i2.2200 (consultado el 14 de mayo de 2021).

25 CIACCAGLIA, (2019), p. 4.

26 ANGUIANO JIMÉNEZ, J. M. (2018), "Blockchain: Fundamentos y perspectiva jurídica. De la confianza al consenso", Diario La Ley, no 18, Sección Ciberderecho, Wolters Kluwer, p. 1, https://iariolaley.laleynext.es/Content/Documento.aspx?params=H4sIAAAAAAAEAMtM SbF1CTEAAiMzM0sjI7Wy1KLizPw8WyMDQwsDU0Mztbz81NQQF2fb0ryU1LTMvNQU kJLMtEqX_OSQyoJU27TEnOJUtdSk_PxsFJPiYSYAAGwoZ6xjAAAAWKE (consultado el 11 de mayo de 2021). 
GÓMEZ REQUENA, (2018), pp. 114-115.

CASANUEVA CAÑETE, D. y LÓPEZ DE LA CRUZ, N. (2018), "El concepto de criptomoneda y breves consideraciones en torno a su tributación", VI Encuentro de Derecho Financiero y Tributario "Tendencias y retos del Derecho Financiero y Tributario", Instituto de Estudios Fiscales, Madrid, p. 79.

SUBIRANA, (2018), p. 49.

0 PRENAFETA RODRÍGUEZ, J. (2016), "Smart contracts: aproximación al concepto y problemática legal básica", Diario La Ley, $\mathrm{n}^{\circ} 8824$, p. 2, https://diariolaley.laleynext.es/Content/ Documento.aspx?params $=$ H4sIAAAAAAAEAMtMSbF1CTEAAiNjM0sjQ7Wy1KLizPw8W yMDQzMDC2OwQGZapUt-ckhlQaptWmJOcapack5qYpFLYkmqc2JOal5KYpFtSFFpKgAq 0AikTAAAAA $==$ WKE (consultado el 10 de mayo de 2021).

ANGUIANO JIMÉNEZ, (2018), "Blockchain", p. 20.

La revista está disponible en http://www.extropy.org/publications.htm; el artículo se titula "Smart Contracts: Building Blocks for Digital Free Markets" y se encuentra disponible en https://www.fon.hum.uva.nl/rob/Courses/InformationInSpeech/CDROM/Literature/LOTwi nterschool2006/szabo.best.vwh.net/smart_contracts_2.html (ambas fuentes consultadas el 12 de abril de 2021).

3 Literalmente se dice que "the contract, a set of promises agreed to in a "meeting of the minds", is the traditional way to formalize a relationship. (...) New institutions, and new ways to formalize the relationships that make up these institutions, are now made possible by the digital revolution. I call these new contracts "smart", because they are far more functional than their inanimate paper-based ancestors. (...) A set of promises, specified in digital form, including protocols within which the parties perform on these promises. (...) The basic idea of smart contracts is that many kinds of contractual clauses (...) can be embedded in the hardware and software we deal with, in such a way as to make breach of contract expensive (if desired, sometimes prohibitively so) for the breacher".

VILLALBA SÁNCHEZ, A. (2019), "El principio de transparencia en la ejecución automatizada del contrato de trabajo: una aproximación jurídica a la tecnología ‘blockchain' y a la inteligencia artificial", Revista Española de Derecho del Trabajo, $\mathrm{n}^{\circ}$ 224, Editorial Aranzadi, S.A.U., BIB $2019 \backslash 9021$, p. 4.

35 GONZÁLEZ-MENESES ROBLES, M. (2020), “'Smart contracts': ¿hacia una economía sin derecho contractual?", Aranzadi digital, nº 1, Editorial Aranzadi, S.A.U., BIB 2020/12401, p. 5. Textualmente el autor dice que "we need a protocol that guarantees that service will be rendered if payment is made, and viceversa".

3 A título ejemplificativo, partidarios de este criterio se muestran O'SHIELDS, R. (2017), Smart contracts: Legal Agreements for the Blockchain, 21 North Carolina Banking Institute, 177, pp. 179, https://scholarship.law.unc.edu/ncbi/vol21/iss1/11 (consultado el 23 de abril de 2021) y TAPSCOTT, D. y TAPSCOTT, A. (2016), Blockchain revolution: How the Technology Behind Bitcoin is changing money, business, and the world, Penguin Random House, p. 102.

8 Pronunciamiento contenido en el sitio web del Banco de España, en https://clientebancario.bde.es/pcb/es/menu-horizontal/actualidadeducac/actualidad/temasint eres/Las_criptomoned_ba71ad627517161.html (consultado el 12 de abril de 2021).

GONZÁLEZ-MENESES ROBLES, (2020), p. 6.

ECHEBARRÍA SÁENZ, (2017), p. 70.

LEGERÉN-MOLINA, A. (2018), "Los contratos inteligentes en España. La disciplina de los smart contracts", Revista de Derecho Civil, vol. V, no 2 (abril-junio), Estudios, pp. 196-197, https://www.nreg.es/ojs/index.php/RDC/article/view/320/267 (consultado el 22 de abril de 2021) y CLACK, C. D., BAKSHI, V. A., BRAINE, L. (2016), "Smart Contract Templates: foundations, design landscape and research directions", p. 3, https://arxiv.org/pdf/1608.00771 v2.pdf (consultado el 22 de abril de 2021).

IBÁÑEZ JIMÉNEZ, J. W. (2018), "Smart contract y notariado español: algunas claves orientadoras", La Ley Mercantil, no 48, pp. 1-17.

RASKIN, M. (2017), "The law and legality of smart contracts", Georgetown Law Technology Review, $\mathrm{n}^{\circ}$ 304, p. 310, https://papers.ssrn.com/sol3/papers.cfm?abstract_id=295 9166 (consultado el 13 de abril de 2021), distingue entre "strong and weak smart contracts. Strong smart contracts have prohibitive costs of revocation and modification, while weak smart 
CONCEPTUALIZACIÓN DE LOS CONTRATOS INTELIGENTES O AUTOEJECUTABLES BASADOS EN LA TECNOLOGÍA... Adoración CASTELLANO GARCÍA

36

contracts do not. This means that if a court is able to alter a contract after it has been executed with relative ease, then it will be defined as a weak smart contract. If there is some large cost to altering the contract in a way that it would not make sense for a court to do so, then the contract will be defined as strong".

44 RASKIN, (2017), p. 310, nota al pie 14, referenciando a CLACK, BAKSHI \& BRAINE, (2016), p. 4, quien diferencia entre "traditional and non-traditional methods of enforcement. (...) traditional means of enforcement (act) (...) through institutions like arbitration or courts of law - these are weak smart contracts in our classification scheme, because the costs to change or revoke the contract are not high enough to proscribe courts or arbitrators from doing so. (And) they define non-traditional means of enforcement as those through "tamper-proof" technology" (...). This smaller set of smart contracts is what I deem the strong variety".

45 HERNÁNDEZ MARTÍNEZ, (2020), p. 15.

46 El articolo 8-bis, 1. de Decreto-Legge 14 dicembre 2018, n. 135. Disposizioni urgenti in materia di sostegno e semplificazione per le imprese e per la pubblica amministrazione. (18G00163) (GU Serie Generale n.290 del 2018), establece que se trata de "un programma per elaboratore che opera su Tecnologie basate su registri distribuiti e la cui esecuzione vincola automaticamente due o più parti sulla base di effetti predefiniti dalle stesse. Gli smart contract soddisfano il requisito della forma scritta previa identificazione informatica delle parti interessate".

47 De conformidad con el art. 23 de la Ley 34/2002, de 11 de julio, de servicios de la sociedad de la información y de comercio electrónico. BOE n $\mathrm{n}^{\circ}$ 166/2002 (en adelante, LSSI), "Los contratos celebrados por vía electrónica producirán todos los efectos previstos por el ordenamiento jurídico, cuando concurran el consentimiento y los demás requisitos necesarios para su validez. (...) Siempre que la Ley exija que el contrato o cualquier información relacionada con el mismo conste por escrito, este requisito se entenderá satisfecho si el contrato o la información se contiene en un soporte electrónico".

48 LEGERÉN-MOLINA, (2018), p. 195.

49 FOZ GIRALT, X., MATINERO TOR, J., MORALES CÁCERES, J.R., CARRASCOSA COBOS, C. (2017), Aspectos legales de los ICOS, Smart Contracts y DAO. In Blockchain: La revolución industrial de Internet, Gestión 2000, Barcelona, p. 178.

50 GONZÁLEZ-MENESES ROBLES, (2020), pp. 1-2.

51 DÍAZ DÍAZ, (2019), p. 6. En un sentido similar pero mucho más genérico se pronuncia FELIU REY, J. (2018), "Smart Contract: Concepto, ecosistema y principales cuestiones de Derecho privado", La Ley Mercantil, $\mathrm{n}^{\circ}$ 47, cuando sostiene que nos encontramos ante un "programa informático que ejecuta órdenes predefinidas cuando ciertas condiciones dentro del sistema son reunidas".

52 GARCÍA MEXÍA, P. (Dir.), ARANDA BRIONES, B. (coord.) y ALCAIDE SOLER, F. (coord.) (2018), Criptoderecho. La regulación de Blockchain, LA LEY, Wolters Kluwer, p. 59.

53 RASKIN, (2017), pp. 309-310, literalmente sostiene que "a smart contract is an agreement whose execution is automated. This automatic execution is often effected through a computer running code that has translated legal prose into an executable program. This program has control over the physical or digital objects needed to effect execution (...) (therefore) does not rely on the state for enforcement, but is a way for contracting parties to ensure performance".

54 GÓMEZ REQUENA, (2018), pp. 117-118.

55 LEGERÉN-MOLINA, (2018), pp. 196 y 201.

56 Nota informativa "Abogacía futura 2020: Áreas de negocio emergentes", p. 34, https://www.abogacia.es/wp-content/uploads/2019/11/Abogacia-futura-2020-Areas-de-ne gocio-emergente.pdf (consultado el 13 de abril de 2021).

57 Según lo dispuesto en el art. 59.1 apartado f) (vigente hasta el 31 de diciembre de 2021) o q) (vigente a partir del 1 de enero de 2022) del Real Decreto Legislativo 1/2007, de 16 de noviembre, por el que se aprueba el texto refundido de la Ley General para la Defensa de

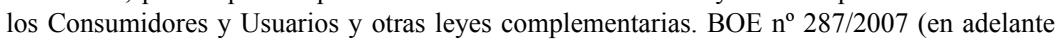
TRLGDCU), es "todo instrumento que permita al consumidor o usuario y al empresario almacenar información que se le haya dirigido personalmente de forma que en el futuro pueda consultarla durante un período de tiempo acorde con los fines de dicha información y que permita su fiel reproducción. Entre otros, tiene la consideración de soporte duradero, el papel, 
las memorias USB, los CD-ROM, los DVD, las tarjetas de memoria o los discos duros de ordenador, los correos electrónicos, así como los mensajes SMS".

58 ANGUIANO JIMÉNEZ, (2018).

59 Algunos de los lenguajes de programación más conocidos son el Bitcoin Script y Solidity, que utilizan las criptomonedas Bitcoin y Ethereum, respectivamente. Son lenguajes de índole informática que permiten programar acciones en la blockchain de cada moneda virtual, es decir, interpreta las instrucciones que el usuario introduce en el programa y las dispone para su ejecución. Para más ahondamiento en la cuestión se aconseja consultar https://es.cointelegraph. com/explained/what-is-bitcoin-script-the-bitcoin-programming-language y https://es.cointeleg raph.com/explained/solidity-the-programming-language-of-the-ethereum

60 MADRID PARRA, (2020), p. 8

61 OTERO MOREIRAS, I. (2019), "Análisis jurídico de los smart contract", LEGALTECH TOUR: TOUR 2 BLOCKCHAIN, LegalToday, https:/www.legaltoday.com/legaltech/ novedades-legaltech/analisis-juridico-de-los-smart-contract-2019-05-23/ (consultado el 26 de abril de 2021). Para mayor ahondamiento en esta categoría contractual se aconseja consultar RODRÍGUEZ, N. (2019), “Qué son los contratos ricardianos? Guía completa”, 101 Blockchains, en https://101blockchains.com/es/contratos-ricardianos/\#: :text=El\%20contrato \%20ricardiano\%20es\%20un,ser\%20 ejecutado\%20por\%20el\%20software (consultado el 26 de abril de 2021).

62 De conformidad con lo sentado en el art. 3 apartado 11 del Reglamento (UE) n ${ }^{\circ}$ 910/2014 del Parlamento Europeo y del Consejo de 23 de julio de 2014, relativo a la identificación electrónica y los servicios de confianza para las transacciones electrónicas en el mercado interior y por el que se deroga la Directiva 1999/93/CE. Diario Oficial de la Unión Europea L. 257/73, es aquella que cumple lo siguientes requisitos: "a) estar vinculada al firmante de manera única; b) permitir la identificación del firmante; c) haber sido creada utilizando datos de creación de la firma electrónica que el firmante puede utilizar, con un alto nivel de confianza, bajo su control exclusivo, y d) estar vinculada con los datos firmados por la misma de modo tal que cualquier modificación ulterior de los mismos sea detectable".

63 ANGUIANO JIMÉNEZ, (2018), 'Smart Contracts'.

64 MADRID PARRA, (2020), p. 9.

65 DÍAZ DÍAZ, (2019), p. 11 e IBÁÑEZ JIMÉNEZ, (2018).

66 WERBACH, K. y CORNELL, N. (2017), "Contracts Ex Machina”, Duke Law Journal, vol. 67 , p. 335, https://scholarship.law.duke.edu/cgi/viewcontent.cgi?article=3913\&context $=\mathrm{d}$ lj (consultado el 8 de mayo de 2021).

67 MOLINA PÉREZ-TOMÉ, S. (2019), "Los smart contracts no son contratos ni son inteligentes", LEGALTECH TOUR: TOUR 2 BLOCKCHAIN, LegalToday, https://www.legaltoday.com/legaltech/novedades-legaltech/los-smart-contracts-n o-son-contratos-ni-son-inteligentes-2019-03-12/ (consultado el 29 de abril de 2021).

68 SKLAROFF, J. M. (2017), "Smart Contracts and the Cost of Inflexibility", University of Pensilvania Law Review, vol. 166, pp. 292-293, https:/papers.ssrn.com/sol3/papers.cfm?abstr act id=3008899 (consultado el 8 de mayo de 2021).

69 WERBACH y CORNELL, (2017), p. 366.

70 Se encuentran recogidos en los arts. 1265-1270 del Real Decreto de 24 de julio de 1889 por el que se publica el Código Civil. BOE nº 206/1889 (en adelante, Cc).

71 La nulidad absoluta está regulada en el art. 83 del TRLGDCU, y se diferencia de la anulabilidad o nulidad relativa, prevista en los arts. $1300 \mathrm{y}$ ss del Cc, en que conlleva la ineficacia de un contrato o una cláusula, donde a pesar de concurrir los requisitos necesarios para su validez, uno o varios se encuentran viciados por dolo, violencia o intimidación, falsedad o error. Para mayor ahondamiento en materia de ineficacia contractual, aconsejamos consultar:LACRUZ BERDEJO, J. L. (2011), Elementos de derecho civil, Tomo II: Derecho de obligaciones, $5^{\mathrm{a}}$ Edición, Dykinson.SÁNCHEZ CALERO, F. J. (2016), Curso de Derecho Civil II. Derecho de obligaciones, contratos y responsabilidad por hechos ilícitos, Valencia, Edición $8^{\text {a }}$, Tirant lo Blanch.

72 PRENAFETA RODRÍGUEZ, (2016), p. 3.

73 WERBACH y CORNELL, (2017), p. 332, literalmente afirma que "the organizations developing the blockchain's software have no power over the network nodes that validate 
CONCEPTUALIZACIÓN DE LOS CONTRATOS INTELIGENTES O AUTOEJECUTABLES BASADOS EN LA TECNOLOGÍA... Adoración CASTELLANO GARCÍA

38

transactions. Even if a court ordered the software developers to issue an update that halted a particular smart contract, the miners would not have to adopt it. And because anyone around the world can set up a mining node on a public blockchain such as Bitcoin or Ethereum, there would be no way for that court to enforce compliance by the miners".

74

75

76

77

78

79

80

81

82

83

84

85

86

87

88

89

90

91

92

93

Art. 23.1 de la LSSI.

95 En el art. 2 de la Ley Modelo de la Comisión de las Naciones Unidas para el Derecho Mercantil Internacional sobre Firmas Electrónicas con la guía para su incorporación al derecho interno 2001, en https:/uncitral.un.org/sites/uncitral.un.org/files/media-documents/uncitral/es/ml-elec sig-s.pdf (consultado el 22 de mayo de 2021) se dice que "por 'firma electrónica' se entenderán los datos en forma electrónica consignados en un mensaje de datos, o adjuntados o lógicamente asociados al mismo, que puedan ser utilizados para identificar al firmante en relación con el mensaje de datos e indicar que el firmante aprueba la información recogida en el mensaje de datos".

96 Entre los defensores de este criterio, véase a título ejemplificativo HERNÁNDEZ MARTÍNEZ, (2020), p. 17.

97 LEGERÉN-MOLINA, (2018), p. 213, nota al pie 55.

98 O'SHIELDS, (2017), p. 186.

99 Art. 101 del TRLGDCU. 
100 Art. 28.1 de la LSSI, interpretado en FERTSYAK, I. (2020), “Contratos inteligentes: Análisis jurídico desde el marco legal español”, Revista Electrónica del Departamento de Derecho de la Universidad de la Rioja, $\mathrm{n}^{\circ}$ 18, p. 217, http://doi.org/10.18172/redur.4898 (consultado el 30 de mayo de 2021).

101 Vid. Nota al pie 72.

102 En contraposición al error impropio u obstativo, en el que la voluntad se forma correctamente pero se produce es una simple equivocación en virtud de la cual se dice algo distinto a lo querido; en el error propio, previsto en el art. 1266 del Cc, sí se forma de manera incorrecta la voluntad de alguna de las partes respecto a una condición esencial o determinante en la contratación, y se distinguen tres tipos según recaiga sobre el objeto, la persona con la que se contrata o los motivos de la contratación. Para mayor ahondamiento en esta cuestión se aconseja consultar DE CASTRO Y BRAVO, F. (1985), El negocio jurídico, Civitas, S.A., Madrid, pp. 108-116, https://www.todojuristas.com/blog/wp-content/uploads/2016/04/EL_NE GOCIO_JURIDICO_-_Federico_de_Castro_y_Bravo.pdf (consultado el 28 de mayo de 2021).

103 En este sentido se pronuncia FELIU REY, (2018).

104 LEGERÉN-MOLINA, (2018), p. 228, nota al pie 94.

105 PRENAFETA RODRÍGUEZ, (2016).

106 MADRID PARRA, (2020), p. 23.

107 ECHEBARRÍA SÁENZ, (2017), p. 73.

108 Art. 1262 del Cc.

109 Art. 29 de la LSSI.

110 BOURQUE, S. y FUNG LING TSUI, S. (2014), “A lawyer's introduction to smart contract", Scientia Nobilitat Reviewed Legal Studies, n. 201, p. 13, https:/github.com/joequant/scms/blob/master/doc/pdfs/A\%20Lawyer's\%20Introduction\% 20 to $\% 20$ Smart $\% 20$ Contracts.pdf (consultado el 30 de mayo de 2021), literalmente indica que un contrato inteligente "is not physically located, nor administered in any one specific physical location (...) In a sense, it is both everywhere and nowhere".

111 Arts. 24 de la LSSI y 25.2 del Reglamento (UE) n ${ }^{\circ}$ 910/2014 (Ex. art. 3.8 de la derogada Ley 59/2003, de 19 de diciembre, de firma electrónica. BOE nº 304/2003).

112 O'SHIELDS, (2017), p. 190, literalmente sostiene que "this should not be burdensome to developers of this technology in that they will need to provide a natural language version of the contract to the parties to obtain mutual consent".

113 MADRID PARRA, (2020), p. 21.

114 Arts. 1271-1273 del Cc interpretados en LEGERÉN-MOLINA, A. (2018), p. 215.

115 SAVELYEV, A. (2016), "Contract Law 2.0: Smart Contracts as the Beginning of the End of Classic Contract Law”, National Research University Higher School of Economics, p. 20, https ://wp.hse.ru/data/2016/12/14/1111743800/71LAW2016.pdf (consultado 30 de marzo de 2021).

116 Arts. 1274-1277 del Cc.

117 Opinión compartida en CIACCAGLIA, (2019), p. 12, donde se afirma que "en relación con el acuerdo, la causa y el objeto, no parecen plantear problemas particulares. Ciertamente no son diferentes a los que se podrían detectar si nos encontrásemos frente a un contrato "normal"'.

118 MADRID PARRA, (2020), p. 18.

119 Esto es, que no sea necesaria la intervención de terceros, como un banco o entidad de crédito, para autorizar la transacción, ya que "para realizar un contrato autoejecutable necesitamos un instrumento de pago electrónico y que los instrumentos de pago electrónico a distancia no nos resultan útiles, en la medida que requieran la autorización del pago, prueba de identidad y otros factores que excluyan el automatismo" (ECHEBARRÍA SÁENZ, (2017), p. 75).

120 Son múltiples las definiciones que podemos encontrar de las criptomonedas, pudiendo distinguir:El ámbito legal, donde han sido conceptualizadas en el art. 1, modificación 2) apartado d) 18) de la Directiva (UE) 2018/843 del Parlamento Europeo y del Consejo de 30 de mayo de 2018por la que se modifica la Directiva (UE) 2015/849 relativa a la prevención de la utilización del sistema financiero para el blanqueo de capitales o la financiación del terrorismo, y por la que se modifican las Directivas 2009/138/CE y 2013/36/UE. Diario Oficial de la Unión Europea L 156/43, como una "representación digital de valor no emitida ni garantizada por un banco central ni por una autoridad pública, no necesariamente asociada a una moneda establecida legalmente, que no posee el estatuto jurídico de moneda o dinero, 
pero aceptada por personas físicas o jurídicas como medio de cambio y que puede transferirse, almacenarse y negociarse por medios electrónicos".La óptica institucional, en la cual, a título ejemplificativo, el Banco de España las concibe como "un conjunto heterogéneo de instrumentos de pago innovadores que, por definición, carecen de un soporte físico que los respalde" y que encontrándose "amparadas en una de las tecnologías más innovadoras del momento -la blockchain o cadena de bloques-permiten compras, ventas y otras transacciones financieras". Tal como se indica en GORJÓN, (2014), p. 1, y en el sitio web de dicho organismo https://clientebancario.bde.es/pcb/es/menu-horizontal/actualidadeducac/actualidad/ temasinteres/Las_criptomoned_ba71ad627517161.html (consultado el 29 de mayo de 2021).Y la perspectiva doctrinal, en donde dentro de gran la variedad de pronunciamientos consideramos muy clarificador el sentado en PUJALTE MÉNDEZ-LEITE, H. (2017), "La proliferación de las monedas virtuales en un entorno desregulado: su impacto en la fiscalidad", Revista de Fiscalidad Internacional y Negocios Transnacionales, $\mathrm{n}^{\circ}$ 6, parte Cuestiones prácticas, Editorial Aranzadi, S.A.U., Cizur Menor, p. 2. En concreto, afirma que "las monedas virtuales que existen en la actualidad (...) no son monedas fiduciarias, es decir, no son monedas de curso legal emitidas por una autoridad central ni, consecuentemente, respaldadas por la regulación vigente en materia de cobros y pagos. A diferencia del efectivo que respalda el dinero electrónico emitido habitualmente, que se deposita en instituciones financieras que siguen todas las regulaciones y quedan supervisadas por la misma autoridad que controla la moneda nacional que lo respalda, las monedas virtuales no gozan de estas garantías".

121 ECHEBARRÍA SÁENZ, (2017), p. 70.

122 LEGERÉN-MOLINA, (2018), p. 235.

123 Al igual que sucede con las criptomonedas, existe una gran variedad de nociones de dinero electrónico y a este respecto procede diferenciar:El sector legal, donde los arts. 2, apartado 2 de la Directiva 2009/110/CE del Parlamento Europeo y del Consejo, de 16 de septiembre de 2009, sobre el acceso a la actividad de las entidades de dinero electrónico y su ejercicio, así como sobre la supervisión prudencial de dichas entidades, por la que se modifican las Directivas 2005/60/CE y 2006/48/CE y se deroga la Directiva 2000/46/CE. Diario Oficial de la Unión Europea L 267/7, y 1, apartado 2 de la Ley 21/2011, de 26 de julio, de dinero electrónico. BOE $n^{\circ} 179 / 2011$, establecen que se trata de "todo valor monetario almacenado por medios electrónicos o magnéticos que representa un crédito sobre el emisor, se emite al recibo de fondos con el propósito de efectuar operaciones de pago, (...) y que es aceptado por una persona física o jurídica distinta del emisor de dinero electrónico".Y el ámbito doctrinal, donde no existe unanimidad, porque un sector defiende una amplia conceptualización basada en entenderlo como "instrumento de pago reflejado en un soporte informático y que, a través de transferencias electrónicas de fondos, persigue la misma finalidad que el dinero tradicional, dependiendo la efectividad del mismo, de su realización" (BERROCAL LANZAROT, A. I. (2012), "El dinero electrónico y las entidades de dinero electrónico tras las reformas operadas por la ley 21/2011, de 26 de julio y por el real decreto 778/2012, de 4 de mayo", Revista de la contratación electrónica, $\left.\mathrm{n}^{\circ} 118, \mathrm{p} .4\right)$. Y por el contrario, otro sector se decanta por una postura más restringida, en base a la cual lo define como un "procedimiento técnico que sirve como depósito electrónico del valor monetario, utilizado para realizar pagos a entidades distintas de la institución emisora, como un instrumento al portador prepagado, sin necesidad de implicar a cuentas bancarias en la transacción" (Informe anual del Banco Central Europeo (1998), Apartado Glosario, p. 160, htt ps:/www.bde.es/bde/es/, consultado el 30 de mayo de 2021). Y en consonancia se sostiene que pretende remplazar el papel moneda "por un conjunto de bits representativos de un determinado valor denominados tokens, que se almacenan en el disco duro de un ordenador y pueden ser transmitidos a través de Internet para efectuar pagos", si bien, "previamente se ha de producir la validación por parte de una entidad financiera" (MADRID PARRA, A (2018), "Dinero electrónico revisitado", Revista de Derecho Bancario y Bursátil, n 151, parte Artículos, BIB 2018/10809, Editorial Aranzadi, S.A.U., Cizur Menor, p. 6, nota al pie 17).

124 ECHEBARRÍA SÁENZ, (2017), p. 80.

125 GONZÁLEZ-MENESES ROBLES, (2020), p. 6.

126 Art. 1462 del Cc.

127 Arts. 1463 y 1464 del Cc, respectivamente.

128 TUR FAÚNDEZ, C. (2018), Smart contracts. Análisis jurídico, Editorial Reus, Madrid, p. 116. 
129 Arts. 1157, 1166-1167 y 1169-1171 del Cc.

130 LEGERÉN-MOLINA, (2018), pp. 233-234.

131 Art. 1158-1159 del Cc.

132 Se encuentran regulados en el art. 1164 del Cc y se trata de una figura que abarca aquellos casos en los cuales un sujeto crea la apariencia de que es el verdadero acreedor del deudor, para que este quede persuadido de que si le paga quedará liberado de la obligación que pesa sobre él, según DÍEZ-PICAZO y PONCE DE LEÓN, L. (1996), Fundamentos del Derecho Civil Patrimonial, Tomo II, Civitas, Madrid, p. 494-495.

133 En base a lo dispuesto en el art. 1175 del Cc "el deudor puede ceder sus bienes a los acreedores en pago de sus deudas. Esta cesión, salvo pacto en contrario, sólo libera a aquel de responsabilidad por el importe líquido de los bienes cedidos".

134 Según el art. 1849 del Cc consiste en que "si el acreedor acepta voluntariamente un inmueble, u otros cualesquiera efectos en pago de la deuda, (...) queda libre el fiador".

135 Está regulada en los arts. 1172-1174 del Cc, y es concebida en el Fundamento de Derecho 3. de la Sentencia del Tribunal Supremo - Sala Primera, de lo Civil n ${ }^{\circ} 384 / 1985$, de 25 de octubre, como "la designación o el señalamiento de la deuda a la que se haya de aplicar la prestación verificada por el deudor, lo que exige la coexistencia previa de deudor y acreedor y de una pluralidad de deudas derivadas de las relaciones obligacionales mediantes entre los mismos". 